Hispania, 2020, vol. LXXX, n. ${ }^{\circ} 265$, mayo-agosto, págs. 405-438 ISSN: 0018-2141, e-ISSN: 1988-8368, https://doi.org/10.3989/hispania.2020.011

\title{
Puerto de Indias e Indias de Roma: los negocios curiales de Fonseca y Rojas en la Sevilla moderna (1591-1617)*
}

\author{
Antonio J. Díaz-Rodríguez ${ }^{1}$ \\ Universidad de Córdoba \\ antonio.diaz@uco.es
}

RESUMEN: Este trabajo presenta los resultados de un estudio de caso sobre un fenómeno hasta ahora desatendido por la historiografía: las compañias de gestión de negocios curiales. En otras palabras, se analiza cómo se estructuraba y cómo funcionaba en la España moderna la intermediación profesional al servicio de particulares para la solicitud de gracias de todo tipo ante la administración pontificia en Roma. Los hombres dedicados a estas actividades eran conocidos como curiales, agentes en un enorme mercado internacional que movía gran cantidad de capital. La Sevilla de los siglos XVI y XVII fue uno de los nodos más activos de este mercado y la compañia de Fonseca y Rojas una de las más notables de Castilla.

* Este artículo ha sido elaborado en el marco del Proyecto I+D HAR2015-68577-P, dirigido por el Dr. Enrique Soria Mesa y financiado por el Ministerio de Economía y Competitividad del Gobierno de España. La investigación ha sido posible gracias a un contrato postdoctoral de la Universidad de Córdoba.

Quiero agradecer las sugerencias y mejoras de los evaluadores anónimos de la revista.

Para la elaboración de este trabajo se han consultado los siguientes fondos, citados a lo largo del mismo por las siglas mencionadas entre paréntesis: Archivo Apostólico Vaticano, Roma (AAV), Archivio di Stato di Roma, Roma (ASR), Archivo de la Catedral de Sevilla, Sevilla (ACSE), Archivo General del Arzobispado de Sevilla, Sevilla (AGAS), Archivo General de Simancas, Simancas, Valladolid (AGS), Archivo Histórico Provincial de Córdoba, Córdoba (AHPCO), Archivo Histórico Provincial de Sevilla, Sevilla (AHPSE), Fundación Museo de las Ferias-Archivo Simón Ruiz, Medina del Campo, Valladolid (FMF-ASR), Biblioteca Nacional de España, Madrid (BNE), Biblioteca de la Universidad de California, Los Ángeles (UCLAL) y Biblioteca de la Universidad de Santiago de Compostela, Santiago de Compostela, La Coruña (BUSC).

${ }^{1}$ ORCID iD: https://orcid.org/0000-0002-9586-4949.

Copyright: (C) 2020 CSIC. Este es un artículo de acceso abierto distribuido bajo los términos de una licencia de uso y distribución Creative Commons Reconocimiento 4.0 Internacional (CC-BY 4.0) 
PAlabras ClaVE: curia romana; Sevilla; beneficios eclesiásticos; dispensas; mercado curial; intermediación.

The "Port of the Indies" and the "Indies" of Rome: Fonseca y Rojas's curial business in Early Modern Seville (1591-1617)

ABSTRACT: This paper presents the results of a case study on a phenomenon hitherto neglected by historiography: curial business management companies. The analysis considers the structure and operations, in Early Modern Spain, of professional intermediation whereby requests for graces of all kinds were submitted on behalf of individuals to the papal administration in Rome. These activities were conducted by agents known as curiales in a huge international market that moved large amounts of capital. Sixteenth-and seventeenth-century Seville was one of the most active hubs in this market, and Fonseca y Rojas one of the major companies in Castile.

KeY WORDS: Roman Curia; Seville; ecclesiastical benefices; dispensations; curial market; brokerage.

CÓMO CITAR ESTE ARTÍCULO/CITATION: Díaz-Rodríguez, Antonio J., «Puerto de Indias e Indias de Roma: los negocios curiales de la compañía Fonseca y Rojas en la Sevilla moderna (1591-1617)», Hispania, 80/265 (Madrid, 2020): 405-438. https://doi. $\operatorname{org} / 10.3989 /$ hispania.2020.011

De manera que el Perú de Roma es Hespaña, y en Roma no ay dinero sino quando viene el correo de Hespaña ${ }^{2}$.

Ningún año habrá que no salgan 600.000 ducados para Roma. Y si las Indias no socorriesen con sus tesoros, no dejara un real en España ${ }^{3}$.

A fines del siglo XVI, Sevilla recibía grandes cantidades de plata y oro procedentes de América, de las que dependía la política imperial hispánica. Una parte de ese dinero engrosaba de forma indirecta las arcas de la Santa Sede a cambio, principalmente, de la expedición de letras apostólicas; breves y bulas que hacían posible llevar a cabo prácticas fundamentales para la dinámica social de la España moderna. En torno a ello no tardó en aparecer un mercado internacional sobre el que se sustentó una fracción notable de las finanzas papales ${ }^{4}$. En él, la capital hispalense se convirtió en un foco centralizador de demanda para todo el cuadrante sudoccidental de la Corona de Castilla. A los profesionales de la intermediación asentados en la ciudad andaluza recurrían solicitantes de gracias de Roma procedentes de toda la diócesis, junto con

\footnotetext{
${ }^{2}$ Carta del Dr. Afonso Álvares Guerreiro a Felipe II, AGS, Estado, leg. 886, s.f.

3 Memorial del cardenal Antonio Zapata, BNE, mss. 13.013, doc. 9.

${ }^{4}$ FORTEA PÉREZ, 2015: 473-508. ROSA, 2013: 31-32.
} 
extremeños, cordobeses, malagueños, canarios o novohispanos. La ciudad albergaba el Puerto de Indias de la Monarquía Católica, pero también era un nodo fundamental de un activo mercado que, en palabras de algunos coetáneos, hicieron de España las Indias de Roma.

Este artículo pretende analizar este mercado de los negocios curiales desde la Sevilla de los siglos XVI y XVII, focalizando la atención en los curiales que ofrecían en ella sus servicios. Con ese nombre eran conocidos estos mediadores profesionales en el ámbito ibérico ${ }^{5}$. No sólo controlaban el acceso de los fieles al complejo aparato de la administración romana y al crédito necesario para la obtención de la mayoría de las gracias, sino también un recurso tan importante en cualquier red comercial como era la información ${ }^{6}$. Contamos apenas con el magnífico estudio que José Antonio Ollero Pina dedicara en esta misma revista a uno de ellos, el converso García de Gibraleón, fascinante personaje a través del cual se atisba el desarrollo de estas redes en torno a la obtención de beneficios eclesiásticos?.

Más allá de algunas primeras aportaciones que hacían pensar en su existencia ${ }^{8}$, el mercado curial es un campo historiográfico aún por desbrozar, lo que no hace fácil la tarea de reconstrucción de la contratación local. En verdad, las múltiples dimensiones de éste lo convierten en una cuestión historiográficamente transversal. En ese sentido, resultan de gran valor como base tanto los estudios sobre el sistema beneficial, como aquellos centrados en los mecanismos de la Dataría y otras instituciones curiales, la fiscalidad pontifica, los circuitos financieros, los agentes de intermediación, etc. ${ }^{9}$

${ }_{5}^{5}$ Sobre los negocios curiales portugueses me remito a DÍAZ RODRÍGUEZ, 72 (Lisboa, 2018): 55-76. Para su equivalente en la Francia de los siglos XVI y XVII, véase PONCET, 2011: 331-346.

${ }^{6}$ Me remito en este sentido a CASADO ALONSO, 10 (Barcelona, 2008): 35-68. La cuestión del crédito a particulares para la expedición de letras apostólicas no cuenta aún con un estudio específico, a pesar de la enorme importancia que se deja ver a partir del análisis de las letras de cambio. A este respecto es sumamente ilustrativa la tesis de PINTO, 2012.

7 OLLERO PINA, 253 (Madrid, 2016): 355-384.

8 PRODI, 73 (Nápoles, 1961): 641-659. OLAECHEA, 1965 (cito a partir de la edición facsímil de 1999). BATAILLON, 1973: 81-93. DELUMEAU, 1975.

${ }^{9}$ Para el caso español contamos con la obra de BARRIO GOZALO, 2010 sobre los beneficios eclesiásticos en el Antiguo Régimen. Para la estructura y mecanismos de las oficinas y tribunales curiales, véase RE, 1998. Existen, asimismo, a día de hoy, un notable número de estudios sobre las finanzas pontificias y la actividad financiera en la Roma moderna: baste señalar obras de referencia como las de REINHARD, 1974: 459-504. PARTNER 88/1 (Oxford, 1980): 17-62. STUMPO, 1985. GUIDI BRUSCOLI, 2007. ROSA, 2013... entre otras muy destacables. Sin embargo, apenas sabemos nada de las cantidades de capital que el mercado creado en torno a la fiscalidad espiritual pontificia movía a través de redes internacionales, sobre el volumen de dinero movido por los intermediarios, sobre todo por estas compañías de negocios curiales. 
Tomada Sevilla como caso de estudio, la metodología seguida ha sido la consulta seriada de protocolos notariales de las décadas de 1590 y 1600, a la búsqueda de escrituras relativas a este tipo de negocios. Esta documentación ha sido cruzada con fuentes diversas de otra procedencia, señaladamente la protocolizada por los notarios del auditor de la Cámara Apostólica, conservada en el Archivio di Stato di Roma, pero también el Archivo Apostólico Vaticano, la Biblioteca Nacional de España, el Archivo de la Catedral de Sevilla o el Archivo Histórico Provincial de Córdoba, entre otros.

\section{LA GÉNESIS DE UNA COMPAÑíA DE CURIALES}

Personajes variopintos, casi siempre fascinantes a su manera, pulularon en los circuitos del mercado curial en el siglo XVI: cazadores de beneficios, judaizantes, testaferros de cardenales y de grandes hombres de negocios, especuladores, letrados de mala nota, falsificadores, chantajistas, riquísimos inversores... Los socios de la compañía curial Fonseca y Rojas no fueron ajenos a este mundillo. Como en otros casos que he podido estudiar, la asociación para la gestión de negocios curiales se generó gracias a la confluencia de personas, habilidades e intereses en la cosmopolita Roma de la segunda mitad del quinientos. En esta ocasión, el encuentro surgió entre un portugués, Jerónimo da Fonseca ( $c a$. 1546-1596) y un español, Bartolomé Olalla de Rojas (ca. 1548-1617). Ambos formarían uno de los canales de intermediación curial más activos de la década de 1590, aunque merece la pena retroceder unos años para analizar el origen de estos corresponsales y la génesis de una relación de amistad que daría pie a la constitución de su compañía.

Bartolomé Olalla de Rojas nació en el seno de una familia de los grupos medios de Granada. Su origen, algo oscuro, contrasta con el pintoresquismo de su vida posterior. Sabemos por él mismo que quedó huérfano joven y fue el mayor de sus hermanos quien ejerció el papel de padre, costeándole los estudios y consiguiéndole una capellanía a cuyo título poder ordenarse ${ }^{10}$. Resulta interesante señalar la coincidencia de nombre y apellidos entre su hermano Martín Ruiz de Rojas y un potente arrendador de las rentas del reino de Granada de dos generaciones antes, procedente de La Mancha y al que Ángel Galán da como probable converso; quizá se tratara de su abuelo materno ${ }^{11}$.

${ }^{10}$ Testamento del doctor Bartolomé Olalla de Rojas, AHPSE, Protocolos Notariales de Sevilla, leg. 12.696, fol. 566r. Este valor social de las capellanías en la Castilla moderna ha sido analizado por SORIA MESA, 2002: 135-148.

${ }^{11}$ GALÁN SÁNCHEZ, 2015: 326-327. En concreto la familia estuvo relacionada de un modo u otro con el negocio de la seda y sus rentas. A este respecto, véase SORIA MESA, 253 (Madrid, 2016): 415-444.

Hispania, 2020, vol. LXXX, n. ${ }^{\circ} 265$, mayo-agosto, págs. 405-438, ISSN: 0018-2141, e-ISSN: 1988-8368 https://doi.org/10.3989/hispania.2020.011 
Poco después de licenciarse, Bartolomé Olalla de Rojas marchó a Italia, donde obtuvo luego el título de doctor en Derecho. Allí, parece haber estado vinculado de un modo u otro al cardenal Alejandro Farnesio. De hecho, con su aval presentó el 7 de marzo de 1575, una súplica para enviar a España ciertas reliquias para la colección de Felipe II en El Escorial ${ }^{12}$. Es probable que gracias a este vínculo consiguiera el beneficio de la iglesia romana de Santa Maria in Grottapinta, poco después elevado a rectoría parroquial ${ }^{13}$. Templo y curato pertenecían al patronato de una rama de los Orsini encabezada por el sobrino segundo del cardenal Farnesio, Paolo Giordano, duque de Bracciano, en cuya clientela parece haberse introducido con fuerza Rojas.

A consecuencia de ello, el granadino se vio envuelto como participante en uno de los escándalos más sonados de la Roma de la época, novelado o dramatizado en varios idiomas por autores como John Webster, Stendhal o Ludwig Tieck. Tras asesinar en 1576 a su esposa, Isabel de Médicis, el duque de Bracciano se había instalado en Roma, donde comenzó una aventura con Vittoria Accoramboni. Ella estaba casada con Francesco Peretti dal Monte, sobrino del cardenal Felice Peretti. En 1581 el marido fue asesinado, dejando libre a madama Accoramboni para contraer nuevas nupcias. El propio Olalla de Rojas fue quien celebró a toda prisa el matrimonio en su iglesia, anexa al palacio Orsini, según las testificaciones obtenidas por monseñor Bernardino Cotta, encargado de la investigación del caso. Poco antes ese mismo día, el rector de Grottapinta había dado sepultura a un criado muerto violentamente a las puertas del palacio ${ }^{14}$.

Cuatro años después, el cardenal Peretti fue elevado al solio pontificio como Sixto $\mathrm{V}$ y no tardó en querer vengar la muerte de su sobrino, junto con otros parientes. Ese mismo año falleció Orsini en Saló y Vittoria Accoramboni fue muerta por encargo en Padua. Como mero actor secundario, la intervención de Bartolomé Olalla de Rojas en todo esto no tuvo consecuencias aparentes, más allá de la recriminación por incumplir el decreto conciliar relativo a las amonestaciones matrimoniales.

Probablemente, en la década de los ochenta el doctor Rojas mantenía ya estrechos contactos en el entorno de la Cofradía de la Resurrección y de los poderosos Farnesio. En este círculo, era constante la actividad de mercadeo con beneficios eclesiásticos, la gestión de dispensas matrimoniales, la compra

12 GARCÍA DE ANDRÉS, 2008: 727.

${ }^{13}$ Debió de ser presentado al mismo en torno a 1574-1575, puesto que sabemos que lo resignó al cabo de dieciséis años, lo que coincidiría con su marcha a Sevilla a fines de 1590 y con la documentación conservada al respecto entre los papeles de la familia Orsini, conservados en la Biblioteca de la Universidad de California, fechados en 1591. UCLAL, Orsini Family Papers, caja 117, carpeta 1. Consultado online el 15 de agosto de 2018 en: http://www.oac.cdlib. org/findaid/ark:/13030/kt0n39q6hv/

14 BRIGANTE COLONNA, 2005: 174

Hispania, 2020, vol. LXXX, n. ${ }^{\circ}$ 265, mayo-agosto, págs. 405-438, ISSN: 0018-2141, e-ISSN: 1988-8368 https://doi.org/10.3989/hispania.2020.011 
de oficios venales, de deuda pública pontificia... El crédito necesario para estas negociaciones a menudo procedía del banco del famoso judeoconverso portugués António da Fonseca, con bastantes negocios beneficiales con el cardenal Farnesio, a quien pagaba una pensión de nada menos que 3.400 ducados de oro anuales ${ }^{15}$. Fue precisamente Fonseca quien, a partir de 1583, comenzó a construir para su enterramiento la Capilla de la Resurrección en Santiago de los Españoles, que serviría de sede a la cofradía ${ }^{16}$.

El cargo de prior de la misma lo ocupó entre 1582 y 1588 el baezano don Juan Bejel de Almansa, que en todo este tiempo se desempeñó como un curial muy activo. Entre 1583 y 1585 lo hallamos envuelto en numerosas operaciones, probablemente especulativas, con beneficios eclesiásticos de toda Castilla (pensionados por él tras resignar, para luego casar él mismo las pensiones impuestas a su favor, mecanismo típico de ocultación de una venta). Es lo que hizo con una ración de la catedral de Córdoba, con el priorato de Carmona, con los beneficios sinecuras de San Lorenzo y Paternilla de los Judíos, con la dignidad de abad de la colegiata de Castrojeriz, con el arcedianato de Pedroche... ${ }^{17}$

Esta última operación es especialmente interesante, en tanto que revela toda esta red de contactos comunes con Fonseca y Rojas. El arcedianato de Pedroche había sido dado en Roma a Francisco de Astudillo, a cuya muerte, en 1585. pasó a su pariente don Luis de Toledo, quien aceptó en el traspaso el pago de la pensión prometida por Astudillo a Bejel de Almansa por medio de su procurador, el cardenal Fernando de Médicis. Como veremos más adelante, los Astudillo mantenían en estos mismos años una presencia relevante como curiales en Sevilla y gestionaban beneficios para los Montalvo. Éstos trabajaban para el cardenal Médicis, además de ser socios y parientes de Simón Ruiz, por cuyo banco pasaban muchas de las letras de cambio que posibilitaban las operaciones de Bejel de Almansa, de los Fonseca o del propio Rojas. Es más, al cruzar la información que aporta el testamento de Bejel con la de otras fuentes notariales romanas, se intuye una presencia significativa de la compañía, que debió tener en todo el valle del Guadalquivir, desde Jaén - a través de su hermano Francisco - hasta Sevilla, donde contaba con un deudo, Fernando Ramírez Bejel, como socio corresponsal ${ }^{18}$.

15 Poder otorgado por el cardenal Farnese, ASR, Notai A. C., vol. 6.188, fol. 297v. Sobre el papel de las pensiones eclesiásticas en los ingresos de los cardenales italianos del siglo XVI, me remito al magnífico estudio de MCCLUNG HALLMAN, 1985: 46-65.

16 NELSON NOVOA, 4 (Córdoba, 2014): 349-350.

17 Consensus de beneficios, AAV, Camera Apostolica: Resignationes, libro 290, fol. 14r.; libro 293, fol. 57r.-v. Obligaciones de pago de cédulas bancarias para pensiones, ASR, Notai A. C., vol. 7.083, fols. 575r.-576r. y 667r.

${ }_{18}$ Registro de noticias concernientes a la ejecución del testamento de monseñor don Juan Bejel de Almansa, BUSC, mss. 81. Consultado online el 12 de marzo de 2019 en: http://www. 
Algunos de los negocios de Bejel de Almansa eran derivados al sevillano Juan Bautista de Aguilar ${ }^{19}$. Este último gozaba de cierto reconocimiento como teólogo y escritor latino, si bien una parte importante de su día a día se enfocaba a la tramitación de estos asuntos que se le remitían. Aguilar pertenecía asimismo a la red clientelar de los Farnesio, a quienes dedicó varias obras laudatorias, incluido una sentida elegía cantada (non sine lachrymis) al túmulo del cardenal, fallecido en $1589^{20}$.

Tanto Bejel como Aguilar habían empezado a recurrir al banquero Jerónimo da Fonseca, cofrade de la Resurrección (de hecho, llegó a ocupar, como Bejel, el cargo de prior de la misma) y marido de Violante da Fonseca. Este casamiento lo convertía en sobrino del arriba citado António da Fonseca, fundador de la capilla. Ambos hombres de negocios eran portugueses y conversos, si es que no parientes lejanos por consanguinidad. La sospecha del criptojudaísmo caía también sobre ambos. El hermano de António, Jácome da Fonseca, había abandonado Roma, donde ejercía como banquero de la Curia, para vivir como judío en el Imperio Otomano. Por su parte, contra Jerónimo da Fonseca se presentaron acusaciones póstumas por judaísmo ante la Inquisición italiana, de la mano de su propio sobrino, de un fraile franciscano y otros testigos ${ }^{21}$.

En esta red de relaciones se movía Bartolomé Olalla de Rojas, cuando el doctor Aguilar decidió marchar a Sevilla en 1589. Nueve años antes había quedado vacante una ración en la catedral hispalense, por la muerte de Antonio de Quirós. Tras el mercadeo habitual, Juan Bautista de Aguilar se había hecho con la prebenda en 1582, aunque, como era usual entre curiales, sin la intención de tomar posesión de ella. Le bastaba con los derechos adquiridos gracias a su bula de provisión papal, al menos para ganar una parte de las rentas. No fue hasta siete años más tarde que decidió residir el beneficio. Inició los preparativos del viaje y envió poder a fray Alonso de Aguilar para que tomara posesión personal de la ración en Sevilla en su nombre, cosa que hizo en la reunión capitular del 4 de agosto de 1589.

Presumo que tanto él como Jerónimo da Fonseca tenían planeado reforzar así la corresponsalía con la capital andaluza, desde la que podía controlarse

galiciana.bibliotecadegalicia.xunta.es/es/consulta/busqueda_referencia.cmd?campo=idautor\&idValor $=31801$

19 Registro de noticias concernientes a la ejecución del testamento de monseñor don Juan Bejel de Almansa, BUSC, mss. 81. Consultado online el 12 de marzo de 2019 en: http://www. galiciana.bibliotecadegalicia.xunta.es/es/consulta/busqueda_referencia.cmd?campo=idautor\&idValor $=31801$

${ }^{20}$ A su sobrino, el duque de Parma, dedicó su obra mayor, el Carmen heroicum, un panegírico en quinientos versos para celebrar la victoria de Alejandro Farnesio en el sitio de Maastricht de 1579, o un epigrama sobre sus triunfos contra la Unión de Utrecht. ALCINA, 1995: 23.

${ }^{21}$ NELSON NOVOA, 4 (Córdoba, 2014): 349. 
el grueso de los negocios curiales del suroeste español e, incluso, diócesis ultramarinas. La ciudad era además un importantísimo nodo en los circuitos de crédito de que dependían a fin de cuentas los negocios curiales ${ }^{22}$. Sin embargo, el doctor Aguilar nunca llegó a Sevilla. Una escueta nota en un libro del cabildo da cuenta de su final: «Requiescat in pace, que viniendo de Roma a Sevilla a poseer la ración se ahogó en la mar por diciembre de $1589 »^{23}$.

Dada la relativa celeridad con que en unos meses la ración fue provista en Bartolomé Olalla de Rojas, es bastante probable que o bien él o bien alguno de los españoles de este círculo hubiera adquirido antes el derecho de regreso a la ración de Aguilar. Era una maniobra muy común para asegurar un beneficio frente a contratiempos de este tipo. Así, en apenas un año, fue Rojas quien lo sustituyó, tomando posesión de la ración en persona ante el cabildo el 7 de diciembre de $1590^{24}$.

Una sustitución tan rápida al frente de los negocios en Sevilla nos indica, por otra parte, el grado de confianza alcanzado ya por entonces entre Rojas y Fonseca. Creo que se trataba de una relación de amistad, más allá del mutuo interés económico. Reflejo de ello es el testamento otorgado en 1596 por Jerónimo da Fonseca. Su único legado a alguien de fuera de la familia fue para Bartolomé Olalla de Rojas. Le dejó dos grandes lienzos italianos ${ }^{25}$, cuyo periplo podemos seguir a través de la documentación, desde la casa del banquero en Roma hasta la de su corresponsal en Sevilla, pasando por Livorno y Cádiz ${ }^{26}$.

En cualquier caso, la actividad del doctor Rojas no comenzó hasta la primavera de 1591. Desconozco los contactos previos con que contaban en la ciudad él o Fonseca para empezar el negocio, pero lo más probable es que estos se hallaran en los tres círculos habituales de las redes de curiales: la

${ }^{22}$ Me limitaré a citar el ya clásico trabajo de OTTE, 1978: 89-112. Añadamos a ello la importancia de Sevilla como centro eclesiástico y el gran número y valor de los beneficios de su archidiócesis, algo que puede verse perfectamente gracias al ya mencionado artículo de OLLERO PINA, 253 (Madrid, 2016): 355-384.

${ }^{23}$ Libro de prebendados, ACSE, libro 382, fol. 68v.

${ }^{24}$ Libro de prebendados, ACSE, libro 382, fol. 68v.

25 «Item lasso iure legati a Bartolomeo Olalla [...] portionario de Siviglia, mio respon$\mathrm{d}$ [ente i] quadri grandi che tengo in casa, u[no di Santa] Susanna, l'altro di Santa Cecilia», citado en NELSON NOVOA, 4 (Córdoba, 2014): 354.

${ }^{26}$ El 29 de agosto de 1598, el Dr. Olalla de Rojas daba poder a Santi Fantoni, Luis Federigui y Juan Álvarez Paje, vecinos de Cádiz, para que en su nombre pudieran recibir de Vicencio Uladi, arraguseo, patrón de la nave San Pablo, una caja larga con un sobre que decía «A Bartolomeo de Olalla de Rojas Racionero de la Santa Iglesia de Sevilla», dentro de la cual venían los dos cuadros grandes de lienzo dejados por la manda testamentaria antes mencionada, uno de Santa Cecilia y el otro de Santa Susana, los cuales había entregado en el puerto de Livorno Rodrigo da Fonseca de Pisa (cuñado del difunto) al patrón de dicho barco. Poder del Dr. Rojas, AHPSE, Protocolos Notariales de Sevilla, leg. 12.587, fol. 1.058v. 
élite y administración eclesiástica, el correo y la banca. A través de lo que refleja la documentación notarial de estos primeros meses de estancia en Sevilla, algo puede intuirse en este sentido, siquiera como mera posibilidad.

El oficio de correo mayor de Sevilla e Indias pertenecía a la familia de Hernando Díaz de Medina desde que en 1576 lo adquiriera su abuelo, Rodrigo de Jerez. Fueron ellos (concretamente su viuda, Isabel Pérez y, en su nombre, el clérigo Luis de Medina) quienes le ofrecieron alquilarle por un año una vivienda en San Nicolás lindera con la del correo mayor ${ }^{27}$. Rojas vivió en ellas hasta septiembre de 1591, en que se trasladó a una gran casa tomada de por vida al cabildo en la calle Abades, en cuya reforma había invertido unos 6.200 ducados $^{28}$. En ella estaría abierto su despacho hasta su muerte en 1617.

Más probablemente la compañía contaba con contactos entre las filas capitulares. De hecho, hasta la llegada de Rojas, la figura más destacable del panorama curial en Sevilla era Baltasar de Astudillo, sobre el que volveré más adelante. Varios de los primeros contratos registrados por Bartolomé Olalla de Rojas a lo largo de 1591 ante el escribano Gaspar de León fueron facilitados por el canónigo don Juan de Medina Villavicencio: una dispensa matrimonial por 550 reales de plata para poder casarse don Nuño de Villavicencio y Cuenca con doña Juana de Villavicencio Villacreces y Cuenca, otra dispensa por 880 reales para poder casarse don Bartolomé Núñez de Villavicencio con doña Beatriz Cabeza de Vaca y Villavicencio... En documentos posteriores hallamos al canónigo Villavicencio como persona de confianza de Bartolomé Olalla de Rojas, nombrado su apoderado para algunos asuntos y, en 1613, su albacea testamentario ${ }^{29}$.

Parece asimismo lógico pensar que, recién instalado en una ciudad que ya contaba con un espacio de intermediación curial consolidado desde décadas antes, optara por una mínima estrategia para darse a conocer frente a otros competidores. En este sentido, es interesante comparar los contratos iniciales (los de 1591) con aquellos firmados años más tarde. En aquellos, ofreció plazos de tramitación y entrega más ajustados de lo habitual, como refleja la tabla 1, en una comparativa entre los plazos concertados para entonces con los más comunes para 1594-1598.

27 Traspaso de casas por Bartolomé Olalla de Rojas, AHPSE, Protocolos Notariales de Sevilla, leg. 12.538, fol. 37r.-v.

${ }^{28}$ Arrendamiento de casa por el cabildo de la catedral de Sevilla, AHPSE, Protocolos Notariales de Sevilla, leg. 12.538, fol. 695r.-701r. Poder otorgado por el doctor Bartolomé Olalla de Rojas, AHPSE, Protocolos Notariales de Sevilla, leg. 12.696, fol. 695r.-701r.

${ }_{29}$ Testamento del doctor Bartolomé Olalla de Rojas, AHPSE, Protocolos Notariales de Sevilla, leg. 12.696, fols. 558r.-568r. 
TABla 1: Plazos de entrega de letras apostólicas

\begin{tabular}{|c|c|c|}
\hline & Contratos de 1591 & Contratos de 1594-1598 \\
\hline Dispensas matrimoniales & 5 meses & $6-7$ meses \\
\hline Resignas y coadjutorías & 6 meses & 8 meses \\
\hline Materias extraordinarias & 8 meses & $8-12$ meses \\
\hline
\end{tabular}

Fuente: AHPSE, legs. 12.535-12.538 y 12.583-12.590. Elaboración propia.

Además, las obligaciones de 1591 son taxativas en cuanto a la fecha exacta de cumplimiento de dichos plazos, mientras que las de seis u ocho años después son bastante más laxas en este extremo. Esto se comprueba no sólo en el lenguaje empleado, sino en la fecha real de entrega, si cruzamos sus datos con las notas y escrituras de cancelación de los conciertos y obligaciones.

Por otra parte, también es cierto que Rojas se mostraba muchísimo más cauto con respecto a la respuesta de sus corresponsales en Roma y al funcionamiento del circuito de crédito y correo en 1591 que años después. Era algo natural, puesto que tomaba por primera vez los mandos de una maquinaria que aún no había puesto a prueba. Enviaba por entonces no una copia o dos de los memoriales con instrucciones a Roma, sino que lo hacía al menos por triplicado. Exigía recoger por escrito y con más detalle en esos primeros contratos las eventualidades que podrían retrasar o malograr el negocio, por causas fuera de su control, tan diversas como:

... çede bacante, o que el correo lo entretubiesen, o matasen, o lo captivaren enemigos, o se detubiere más del tiempo ordinario por ynfortunios, o aguas, o riesgos, constando de todo ello jurídicamente. Y asimismo es condiçión que, si las bulas de la dicha dispensaçión se mojaren, o perdieren, o las tomaren enemigos, en tal caso se saque duplicado de ellas a costa de los dichos contrayentes ${ }^{30}$.

En alguno de los contratos renunciaba expresamente a todas estas salvedades que le amparan tras enumerarlas, se comprometía a devolver el dinero y dejar libre de obligación al contratante si no entregara a su satisfacción la letra apostólica requerida a tiempo. Se trata, por lo general, de los negocios más complicados, en los que no podía ofrecerse un servicio más competitivo reduciendo lo suficiente los plazos de entrega de la bula de manera realista. Un ejemplo de ello es el caso fallido de la solicitud de Gonzalo Pérez de Ábrego, que encargó a Rojas con el máximo sigilo la expedición de cierto tipo de documento en Roma, cuya naturaleza se oculta, en plazo de ocho meses. El 9 de

${ }^{30}$ Concierto entre el Doctor Bartolomé Olalla de Rojas y Alonso Pérez, AHPSE, Protocolos Notariales de Sevilla, leg. 12.535, fol. 979r.

Hispania, 2020, vol. LXXX, n. ${ }^{\circ} 265$, mayo-agosto, págs. 405-438, ISSN: 0018-2141, e-ISSN: 1988-8368

https://doi.org/10.3989/hispania.2020.011 
diciembre de 1592, el curial reconocía la imposibilidad de alcanzar la gracia solicitada y devolvía el dinero adelantado a su cliente ${ }^{31}$.

Su condición de hombre metódico, eficiente en los trámites y claro en las cuentas debió de hacerle ganar rápido un cierto renombre en Sevilla, sobre todo teniendo en cuenta la mala fama que al respecto tenía uno de los principales intermediarios activos en la ciudad durante los veinte años precedentes, Baltasar de Astudillo. Éste obtuvo una canonjía en la catedral de Sevilla en 1564, pero permaneció en Roma como corresponsal de su hermano Gaspar hasta la década de 1570. En 1578 se trasladó a Sevilla al ser provisto en el arcedianato de Jerez y continuó con sus negocios curiales desde allí, si bien le precedía el rumor, entre mercaderes y banqueros, de sus malas artes como especulador de beneficios eclesiásticos y autor de cuentas embrolladas y poco fiables, «que es vergüenza que tal se entienda $\rangle^{32}$, en palabras del mercader Francisco de Montalvo. Si cruzamos la correspondencia de los agentes curiales de Felipe II $^{33}$ con la que recibía el banquero Simón Ruiz desde Roma, la imagen resultante es la de un curial poco digno de confianza. El 26 de junio de 1570, el mencionado Francisco de Montalvo avisaba, tras revisar la contabilidad enviada por Astudillo:

Espantado nos á una cosa tan bárbara, que teníamos aquel hombre por persona más llana y con llaneza pudiera mejor aprovecharse de la hazienda, pues tiempo se le diera siempre como tratara verdad ${ }^{34}$.

El doctor Rojas era todo lo contrario, un hombre obsesionado por el registro y la ordenación de la información. Un dato revelador en este sentido es el hecho de que llevara al día libros de «recuerdos» de todo cuanto acontecía de interés en su entorno: fechas de nacimientos de parientes, bautizos, casamientos, deudas, préstamos, limosnas, obras de caridad descritas en detalle, compras de esclavos, el embarazo de una esclava de su casa, posibles padres de la criatura, maledicencias que llegaban a sus oídos sobre su propia persona... todo ello

${ }^{31}$ Concierto entre el Doctor Bartolomé Olalla de Rojas y Gonzalo Pérez de Ábrego, AHPSE, Protocolos Notariales de Sevilla, leg. 12.538, fol. 1.257r.-1.258r.

32 Carta de Francisco de Montalvo a Simón Ruiz, FMF-ASR, Casa Comercial: Correspondencia, caja 15 , doc. 8 .

${ }_{33}$ Me refiero a la red de agentes que, para la defensa y tramitación de los negocios de los diferentes reinos de la Monarquía Católica, se estructura en estos momentos, a partir de la figura de Francisco Robuster, a quien ya estudiara en profundidad FERNÁNDEZ TERRICABRAS, 2005: 649-668. He tenido oportunidad de analizar tanto este sistema de agencias como el perfil socio-profesional de los agentes en DÍAZ RODRÍGUEZ, 42 (Granada, 2016a): 51-78; 2016b: 57-79, respectivamente. Muchos de estos agentes habían tenido compañías de negocios curiales particulares, cuando no simultaneaban con ellos, tras el nombramiento regio, de forma más discreta.

${ }^{34}$ Carta de Francisco de Montalvo a Simón Ruiz, FMF-ASR, Casa Comercial: Correspondencia, caja 12, doc. 233. 
escrupulosamente ordenado por libros foliados con entradas numeradas. De hecho, él mismo describió en 1613 la meticulosidad con que había llevado también los papeles de sus negocios curiales:

\begin{abstract}
... rompiendo los impertinentes y guardando los más necesarios, los quales boy componiendo y notando en un libro grande que tengo de marca imperial, que contiene trescientas y ochenta y seis ojas, que son setecientas y setenta y dos páginas, en el qual boy notando por recuerdos las quentas y correspondencias que con cada qual he tenido. Y en el dicho libro, entre las páginas ochenta y seis y ochenta y siete he coligado dos quadernos, que el primero contiene quarenta y siete páginas y el segundo quarenta y dos páginas, de las quentas que tube con Antonio Gómez de Roma. Yo apruebo y retifico todo lo por mí escripto y anotado en el dicho libro y dos quadernos y lo demás que se hallare en otros libros menores, cartas, cédulas memoriales y otros qualesquier papeles que yo tubiere ${ }^{35}$.
\end{abstract}

Al final de sus días, el cúmulo de información derivada de estos asuntos era tal que Bartolomé Olalla de Rojas solicitó a sus albaceas que sus libros mayores, cuentas y demás papeles se encerraran en un cofre, «sin permitir que nadie coja alguno dellos». Había de ser sacado de Sevilla para mayor seguridad, encomendándolo a la custodia del abad y canónigos de la abadía del Sacromonte de Granada, para que alguien a sueldo hiciera «un inbentario de los libros y papeles que en el cofre hubieren, poniendo el dicho inbentario sobre los dichos papeles dentro del dicho cofre para con más facilidad hallar el papel que se buscare», y finiquitar de ese modo las cuentas, cerrando negocios y deudas pendientes ${ }^{36}$.

\title{
Fonseca, GoMes Y RoJas: LA EVOLUCIÓN dE LA COMPAÑía A FINES DEL SIGLO XVI
}

El fallecimiento de Jerónimo da Fonseca en 1596 puso fin a la asociación curial establecida con Rojas. Éste envió poder para que los albaceas le remitiesen a España toda la documentación notarial, cuentas, cartas, memoriales y letras de cambio que hubieran quedado

... acerca de los negocios o números que allá tiene para espedir que no ubiere espedido y todas las cantidades de maravedís que yo el dicho racionero le e remitido y hecho remitir para espedir los tales negocios ${ }^{37}$.

\footnotetext{
${ }^{35}$ Testamento del doctor Rojas, AHPSE, Protocolos Notariales de Sevilla, leg. 12.696, fol. $561 \mathrm{r}$.

${ }_{36}$ Testamento del doctor Rojas, AHPSE, Protocolos Notariales de Sevilla, leg. 12.696, fol. $561 \mathrm{r}$.

37 Poder otorgador por el doctor Rojas, AHPSE, Protocolos Notariales de Sevilla, leg. 12.588, fol. 350r.
} 
Obviamente, el flujo comercial no se detuvo por este deceso; es más, se incrementó a partir del año siguiente. Siguiendo las instrucciones de su difunto hermano, António da Fonseca se trasladó a Roma. Allí le esperaba su cuñado, António Gomes, quien parece que ya colaboraba en las expediciones de letras apostólicas $^{38}$.

Durante varios meses la documentación habla apenas de Herederos de Jerónimo de Fonseca y como su representante en Sevilla se presenta Bartolomé Olalla de Rojas. No es hasta 1597 que, en los negocios concertados por éste, empiece a hacerse referencia a António da Fonseca y a António Gomes como sus socios in solidum, cada uno con autorización para actuar en representación de los otros dos sin necesidad de poderes notariales especiales. Así, para la expedición de una bula de coadjutoría de una canonjía para el joven don Tomás Marroquín de Losada, su padre, el contador Pedro Marroquín, se obligó para con Fonseca, Gomes y Rojas por escritura dada el 14 de febrero de 1598. Sin embargo, la letra de cambio de 1.086.366 maravedís, que se envió para esto por vía de la feria de Piacenza el 16 de marzo de ese año, era pagadera «a los herederos o albaseas de Jerónimo de Fonseca» ${ }^{39}$.

El 19 de agosto de 1597, la posición de Bartolomé Olalla de Rojas en Sevilla como hombre de referencia para la tramitación de negocios curiales quedó consolidada gracias a un breve del papa Clemente VIII al efecto, «tan faborable qual nunca antes ni después se ha concedido a curial alguno» ${ }^{40}$.

Para entonces la compañía controlaba un área de negocio extensa, comparada con las de otros curiales coetáneos. La procedencia de su clientela no se circunscribía al reino de Sevilla, sino a prácticamente todo el cuadrante peninsular limitado al norte por la región meridional extremeña (Jerez de los Caballeros, Zafra, Los Santos de Maimona, Azuaga, Zalamea..., de manera excepcional un contrato para la catedral de Plasencia, si bien los clientes eran cordobeses) y, al oeste, por los obispados de Córdoba y Málaga. Además, gestionaba expediciones para vecinos de las islas Canarias y de territorios ameri$\operatorname{canos}^{41}$. Fonseca y Rojas atrajo, pues, clientela más allá del hinterland sevillano inmediato, y esto fue así por varias causas.

${ }^{38}$ En el testamento, Jerónimo da Fonseca menciona esta sucesión: «Antonio mio nepote lo prego che attendi a fare $\mathrm{i}$ conti et esigere e metterli in locho sicuro secondo parerà a Antonio Gomez o investirli in speditioni sintanto venga a Roma Antonio de Fonseca mio fratello, che allora si darà ordine alli negocii». cit. por NELSON NOVOA, 4 (Córdoba, 2014): 355.

39 Obligación otorgada por el contador Pedro Marroquín, AHPSE, Protocolos Notariales de Sevilla, leg. 12.584, fols. 371v.-372r. 561 r.

${ }^{4}$ Testamento del doctor Rojas, AHPSE, Protocolos Notariales de Sevilla, leg. 12.696, fol.

${ }^{41}$ En marzo de 1596 Bartolomé Olalla de Rojas fue contratado por Pedro de Samaniego y doña María Infante Samaniego, vecinos de Méjico, para la expedición de una dispensa matrimonial. En agosto de ese mismo año, era de nuevo contratado por unos vecinos de la ciudad de 
La primera de ellas, por su propia constitución: los Fonseca no dejaban de ser grandes banqueros de la curia con corresponsales como Rojas en otros puntos de la península, eminentemente Lisboa. Recordemos que allí, en la primera mitad de la década de 1590, António da Fonseca actuaba como corresponsal de la compañía, dirigida desde Roma por su hermano Jerónimo. Su perspectiva del mercado debió por fuerza ser distinta de la de otros agentes de menor nivel.

Es más, la segunda causa de su penetración en esos territorios es la propia evolución de estos espacios de negocio en Castilla entre finales del siglo XV y finales del siglo XVII. En las primeras décadas, representantes de bancos italianos en determinadas ciudades de la Península eran casi los únicos que ofrecían circuitos seguros para la tramitación de las letras apostólicas. Era el caso de Giuliano Calvo en la Sevilla de principios del siglo XVI, aunque siguen muy presentes en la segunda mitad de la centuria, verbigracia, con Agustín de Vivaldo en Sevilla, o Jacobo y Otobón de Marín, agentes de la banca Grimaldi, en Córdoba $^{42}$. Es posible documentar las primeras compañías de curiales stricto sensu (o sea, constituidas con este fin exclusivo) en torno a los años 1520-1550 en ciudades de importancia mercantil o financiera como Sevilla, Barcelona, Lisboa, Burgos o Cartagena, bien insertadas en circuitos de crédito y comunicación necesarios a estos menesteres. Desde los años 1590 en adelante, la cobertura del territorio se intensificó: hombres de negocios, clérigos con contactos en Roma y notarios de las audiencias episcopales aprovecharon este espacio de negocio para establecerse como curiales en ciudades medias, por lo general cabezas de diócesis cuyo mercado arrebatarían a compañías como la de los Fonseca en el siglo XVII. La cartografía de contrataciones de Fonseca, Gomes y Rojas para 1598 refleja esto también. Clientes de zonas periféricas, sin presencia detectada aún de curiales próximos, han de dirigirse a Sevilla, directamente o por medio de un apoderado enviado al efecto. En la cercana Córdoba, varios curiales empezaron a ofrecer sus servicios desde unas décadas antes, pero tan sólo gestionaban por entonces los negocios menos complejos (dispensas matrimoniales, sobre todo). En materia beneficial, mucho más exigente desde un punto de vista técnico y financiero, así como en asuntos menos comunes, los solicitantes cordobeses iban a contratar un intermediario a Sevilla.

El volumen de actividad y la amplitud del área de la misma hicieron que Bartolomé Olalla de Rojas hubiera de recurrir a otras personas para la gestión de los negocios. En los últimos años del siglo XVI, contaba en Sevilla con los servicios de Silvestre de Almería y de Gabriel Marino. El primero, viejo conocido de Roma por más de quince años, era su apoderado para asuntos legales.

Méjico, Juan Aguado e Isabel Arias, para otra dispensa matrimonial, AHPSE, Protocolos Notariales de Sevilla, leg. 12.572, fols. 173r. y 290r. Agradezco al doctor Rafael Girón Pascual llamar mi atención en el archivo hacia estas dos referencias.

${ }^{42}$ Sobre estos Marín véase GIRÓN PASCUAL, 2018. 
El segundo le ayudaba con las cobranzas; de hecho, el 22 de junio de 1598 obtuvo poderes generales de administración en el negocio de expediciones curiales para poder cobrar en nombre del racionero y llevar a cabo cualquier diligencia legal, embargo o solicitud de encarcelación por deudas ${ }^{43}$.

Desconozco por ahora si para estas fechas se servía también del jurado Miguel Jerónimo de León, hombre de negocios miembro de una acaudalada familia de más que probable origen converso ${ }^{44}$. Ambos debían de conocerse, puesto que León había ocupado el cargo de mayordomo del cabildo de la catedral de Sevilla ${ }^{45}$. Dos años después, el 9 de julio de 1600, lo encontramos ya como apoderado de Rojas, entregando en su nombre a Francisco Calvarte un breve de dispensa matrimonial y cobrando del mismo los 530.000 maravedís que se adeudaban por ello ${ }^{46}$. En cualquier caso, podría tratarse no de una colaboración estable sino de una cesión de deuda.

Era éste un mecanismo recurrente cuando un curial topaba con una cobranza dificultosa, ya fuera por mora del cliente, ya por residir muy lejos u otros inconvenientes. Básicamente, el curial vendía la deuda y entregaba las bulas al cesionario de los derechos de cobranza, junto con copia de la escritura pública de obligación y poder notarial para ejecutarla en su nombre. En contraprestación, el cesionario le pagaba lo adeudado, quedando con la bula del solicitante deudor en prenda. Sería posible, empero, distinguir entre dos clases distintas de cesionarios en función del montante del capital.

Unos eran simples emisarios que cobraban a razón de unos once reales por jornada desde Sevilla (incluyendo el regreso si era necesario). La posibilidad de entrega a domicilio de las letras apostólicas se negociaba antes de la firma del contrato con los solicitantes. En tales casos, el contrato recogía el lugar de entrega, donde además podía realizarse el pago en vez de en Sevilla, haciéndose cargo de los honorarios la persona enviada por el curial. Esto representaba una ocasión de ganar algo de dinero para algunas personas que partían de Sevilla con destino a la localidad en que se hallaban los clientes de Rojas. Así, por ejemplo, el 9 de febrero de 1598, Jerónimo de Porras, escribano del ayuntamiento de Sevilla se concertó con Rojas para la expedición de una dispensa de

${ }^{43}$ Poder otorgado por Bartolomé Olalla de Rojas, AHPSE, Protocolos Notariales de Sevi1la, leg. 12.586, fol. 388r.

${ }_{44} \mathrm{Al}$ menos en este mismo año el jurado firmaba como fiador en una escritura de venta de un censo de 20.000 maravedís de renta anual en favor del racionero Rojas, AHPSE, Protocolos Notariales de Sevilla, leg. 12.590, fols. 724r.-743r. Sobre el origen converso, véase LOHMANN VILLENA, 1983: 244.

${ }^{45}$ De hecho, es a él en su calidad de mayordomo del cabildo a quien el autor del Quijote hiciera varias libranzas como comisionado para la saca de trigo en 1588. ASTRANA MARÍN, 1952: 265.

${ }^{46}$ Obligación otorgada por Francisco Calvarte, AHPSE, Protocolos Notariales de Sevilla, leg. 12.583, fols. $324 \mathrm{r} .-325 \mathrm{v}$. 
cuarto grado de consanguinidad con que pudieran casarse don Bartolomé de Barrionuevo, vecino de Gibraltar, con doña Estefanía de Mendoza, vecina de Vejer de la Frontera. El breve fue expedido en Roma para Sevilla a mediados de septiembre. El 22 de diciembre Rojas lo remitía con un sacerdote gibraltareño, Juan Gutiérrez, que previamente le había pagado los treinta ducados que montaba la deuda y a quien, además de cesionario, nombraba su apoderado para la entrega del breve y cancelación del contrato, previo pago del salario que se le adeudara en virtud de las cláusulas del mismo ${ }^{47}$.

Otros, en cambio, eran financieros a los que la cesión de la deuda interesaba para su renegociación. El problema de la cobranza no reside en estos casos en la distancia geográfica, sino en la importante cuantía de la suma, de varios cientos de miles de maravedís. Tal vez el poder dado al jurado León, arriba mencionado, oculte una de estas ventas de deuda, cuya escritura de cesión no haya podido localizar. Sí están perfectamente documentadas las compras hechas por los Helguera, ricos cargadores de Indias, de las fracciones impagadas de las deudas de Pedro Mejía, Hernán y Juan Mejía Pacheco con la compañía de Fonseca, Gomes y Rojas por varios negocios beneficiales (la coadjutoría de una canonjía, la resigna de una ración y la imposición de una pensión eclesiástica). A cambio del pago de 1.396.012 maravedís, Pedro de la Helguera y su hijo Lázaro Pérez de la Helguera adquirieron todos los derechos contractuales sobre los Mejía, quedando retenidos en su poder los originales de las bulas que éstos habían encargado a Rojas, así como la lista detallada de cargos, pagos y cambios enviada por António da Fonseca desde Roma ${ }^{48}$.

Algunos curiales iniciaban en el negocio a parientes jóvenes llamados a sucederles algún día, si bien en muy pocos de los casos que he podido examinar hasta ahora estas esperanzas se vieron satisfechas a largo plazo. El escaso interés del hijo de Jerónimo da Fonseca por las expediciones en Roma parece haberse manifestado pronto. Algo más tarde, el pupilo del doctor Rojas en Sevilla demostró también otros intereses.

Durante su estancia en Italia, Bartolomé Olalla de Rojas estuvo en compañía de su hermano Nicolás de Rojas, a quien casó con Anna Romana, hija del parmesano Antonio de Cacchis. Éste falleció en Roma el 10 de octubre de 1575, dejando un hijo de cuatro meses, que, como otros niños romanos nacidos ese año santo, fue bautizado con el peculiar nombre de Jubileo. Pocos meses después, el eclesiástico acogió en su casa a la suegra y al pequeño cuñado de su hermano, al que decidió prohijar. Según el propio testimonio de Rojas, mandó tonsurar al niño en San Juan de Letrán, haciendo que lo registraran en el título

${ }^{47}$ Poder otorgado por Bartolomé Olalla de Rojas, AHPSE, Protocolos Notariales de Sevilla, leg. 12.590, fols. 720r.-v.

${ }_{48}$ Poder otorgado por Bartolomé Olalla de Rojas, AHPSE, Protocolos Notariales de Sevilla, leg. 12.586 , fols. $677 \mathrm{v} .-679 \mathrm{r}$.

Hispania, 2020, vol. LXXX, n. ${ }^{\circ} 265$, mayo-agosto, págs. 405-438, ISSN: 0018-2141, e-ISSN: 1988-8368 https://doi.org/10.3989/hispania.2020.011 
de corona con su apellido, Rojas, en lugar del paterno, Cacchis. Lo envió a estudiar al Colegio Romano de la Compañía de Jesús y, a instancia suya, recibió las cuatro órdenes menores, de manera que en un futuro pudiera optar por vivir de rentas eclesiásticas sin cerrarse la puerta al matrimonio, si así lo prefería. Cuando el doctor Rojas, recién nombrado racionero de Sevilla, decidió partir hacia la capital andaluza, Jubileo de Rojas emprendió viaje con él ${ }^{49}$.

Jubileo cumplía con todos los requisitos para labrarse un porvenir en el mercado curial controlado desde Sevilla: buena formación académica, familia y contactos en Roma, la posibilidad de aprender de la experiencia de su tutor, ordenación eclesiástica para poder tomar en cabeza propia beneficios vacantes..., pero la fascinación ejercida por las noticias del nuevo mundo resultó más poderosa. A los veinticuatro años declaró su intención de pasar a las Indias («lo qual he tenido en deseo desde que vine a esta ciudad de Sevilla desde la de Roma»), para lo cual el curial lo dotó del vestuario y otros enseres necesarios, varios cientos de reales en metálico para establecerse en Perú, y corrió con los cien escudos de oro de gastos del viaje y del flete ${ }^{50}$. En 1613, Jubileo de Rojas malvivía gracias al dinero que mendigaba haciéndose pasar por el hijo bastardo de Bartolomé Olalla de Rojas ${ }^{51}$.

Quien, por el contrario, demostraba no sólo aptitudes de buena gestión, sino interés, era una de las sobrinas del curial, doña Jerónima de Rojas, apenas trece años más joven que su tío. Cuando éste regresó de Roma, ella se trasladó a Sevilla para atender la gestión de su creciente patrimonio. Pronto se hizo indispensable, hasta el punto de pedirle que desoyera el consejo de los parientes de volver a Granada para casarse. Como él mismo reconocería más de veinte años después, terminaría por deberle en parte su fortuna:

... sin su prudencia y buen gobierno y gran custodia (...) yo no tuviera con qué ni de qué hazer testamento, pues en poder de esclavos, amas y criados todo se hubiera consumido y yo estaría empeñado y abreviada mi vida ${ }^{52}$.

Doña Jerónima aceptó el encargo a cambio de un salario de cien ducados mejorado con la reserva para sí de todos los ingresos de albricias de bulas, o sea, la propina que los clientes del curial solían pagarle por la consecución de la letra apostólica cuya expedición habían contratado. Con el dinero de las

49 Interrogatorio sobre la persona de Jubileo de Rojas, AHPSE, Protocolos Notariales de Sevilla, leg. 12.589, fols. 412v.-418v.

50 Ratificación de escrituras otorgada por Jubileo de Rojas, AHPSE, Protocolos Notariales de Sevilla, leg. 12.587, fols. 1.182v.-1.183r.

51 Testamento del doctor Bartolomé Olalla de Rojas, AHPSE, Protocolos Notariales de Sevilla, leg. 12.696, fols. 558r.-568r.

52 Testamento del doctor Bartolomé Olalla de Rojas, AHPSE, Protocolos Notariales de Sevilla, leg. 12.696, fol. 566r. 
albricias compró, entre otras cosas, joyas, un par de cadenas de oro y dos esclavos negros berberiscos, Hamete y Aja (bautizados en la catedral de Sevilla en 1604 como Adriano y Ana, quien dos años después parió a su hijo Jacinto, que pasó a ser también esclavo de doña Jerónima) ${ }^{53}$.

El negocio del doctor Rojas fructificó en estos años a la par que su fortuna personal. Ello le permitió fundar en 1598 una capilla funeraria en la catedral de Sevilla. Llevó a cabo desde entonces una notable estrategia de reinversión del capital que fue acumulando: compró directamente o a través de su hermana, doña Catalina Olalla de Rojas, varios inmuebles, un censo de 6.000 ducados de principal sobre el pósito y bienes de dicha ciudad, un juro de 940.387 maravedís sobre la renta de la seda de Granada en septiembre de $1600^{54}$, etc.

El pontificado hispalense de Niño de Guevara (1601-1609) enmarca asimismo el culmen de la carrera eclesiástica de Rojas. El 17 de julio de 1601 promocionó a una canonjía gracias a la resigna hecha en Roma en su favor por don Francisco de Guardiola ${ }^{55}$. Durante varios meses negoció en el mercado de beneficios la resigna de su ración, en cuya propiedad finalmente sucedió el pintor Diego Vidal de Liendo en 1603, al parecer por entonces en Roma, lo que representa un problema con la fecha de nacimiento del artista hasta ahora establecida por los historiadores del arte (1602), reproduciendo probablemente la referencia de Ceán Bermúdez ${ }^{56}$.

Su ascendiente en la diócesis era notable y su relación con el arzobispo buena, como reflejan su nombramiento como juez sinodal (lo que permitía que le fueran remitidas para su ejecución bulas desde Roma y dirimir otros negocios eclesiásticos) o su influencia para modificar las constituciones sinodales en un aspecto que le afectaba personalmente: «La barba larga que vimos trujo de Roma $\rangle^{57}$. La norma eclesiástica imperante en Sevilla hasta entonces, ordenaba a los clérigos ir completamente afeitados. En opinión del doctor Rojas, una gran barba no desmerecía lo más mínimo su dignidad como eclesiástico, muy al contrario. Decidido a defender esta opinión de cara al sínodo convocado en 1604 , la presentó por escrito en un breve tratado dirigido al arzobispo. No sé si persuadido por sus argumentos o movido por sus propios gustos, Niño de Guevara mandó modificar la norma diocesana, admitiendo el vello facial. En agradecimiento, Rojas le presentó una traducción al castellano encargada a su primo, el doctor Mateo de Rivas Olalla, de la obra del italiano Juan Pierio

53 Testamento del doctor Bartolomé Olalla de Rojas, AHPSE, Protocolos Notariales de Sevilla, leg. 12.696, fol. 566r.

${ }^{54}$ El juro, a 18.000 maravedís el millar, comenzó a rentar a partir de 1601. Entre 1568 y 1600 fue propiedad del colegio de la Compañía de Jesús de Granada, AGS, Contaduría de Mercedes, leg. 546/1, doc. 36 .

${ }_{55}$ Libro de prebendados, ACSE, libro 382, fol. 50v.

${ }_{56}$ Libro de prebendados, ACSE, libro 382, fol. 68v.

57 La referencia es de Alfonso de Carranza en su Discurso contra los malos trajes y adornos lascivos, citado en BARBOSA, 1669: 144. 
Valeriano, Defensa de las barbas de sacerdotes, que, con licencia del cardenal, fue impresa en Sevilla en $1609^{58}$.

El año anterior, Bartolomé Olalla de Rojas había sido elegido rector de la recién fundada cofradía de San Pedro ad vincula, donde dotó con doscientos ducados la festividad de la Inmaculada ${ }^{59}$. Se implicó también en mayor medida en la fundación del Colegio de San Isidoro de Sevilla, para lo que había sido nombrado diputado del cabildo, ofreciendo quinientos ducados de renta anual en beneficios eclesiásticos. Estos generosos donativos, que Rojas se preocupó de desembolsar siempre ante testigos, al contado y en doblones de oro, resultan per $s e$ un indicador interesante de su éxito como curial y del uso publicitario que tenía este tipo de evergetismo. Por su deseo expreso en estas fundaciones y donaciones, cada año un encargado de la cofradía, del colegio, de la abadía del Sacromonte... había de salir a manifestar en público y alta voz tratándose de una misa, o a la persona concreta beneficiaria de su caridad, que tal obra o celebración era posible gracias a la buena memoria de Bartolomé Olalla de Rojas.

En 1610 era preconizado arzobispo de Sevilla don Pedro de Castro, procedente de la silla granadina y acompañado de un círculo de familiares y clientes eclesiásticos de gran interés, como el filólogo Bernardo de Alderete, envuelto en el asunto de los plomos del Sacromonte, o el predicador inmaculista Álvaro Pizaño de Palacios. Bartolomé Olalla de Rojas parece haberse introducido rápidamente en dicho círculo. De hecho, en el magno proyecto del arzobispo Castro de construcción de la Abadía del Sacromonte granadino, Rojas dotó uno de los primeros y más señalados patronatos, por escritura de testamento otorgada en Sevilla el 17 de agosto de $1613^{60}$. Para entonces, firmaba y era citado ya como chantre de la catedral sevillana. En realidad, había adquirido esa misma década los derechos de propiedad futura gracias a la sucesión inalienable que le aseguraba una bula de coadjutoría, pero no parece que llegara a tomar nunca la propiedad antes de su muerte, el 19 de agosto de 1617.

\section{LOS NEgocios CURIALES EN SEVILla A Fines del QUiNiENToS}

Para analizar los distintos tipos de negocios curiales contratados con Rojas, Gomes y Fonseca, así como la significación cuantitativa y pecuniaria de cada

${ }^{58}$ He consultado el ejemplar conservado en la Biblioteca de la Universidad de Sevilla: VALERIANO BOLZANI, 1609.

${ }^{59}$ Fundación de Bartolomé Olalla de Rojas, AGAS, Fondo de la Hermandad de San Pedro ad vincula, leg. 15, exp. 3. Sobre el interesante trinomio curiales-conversos-inmaculismo y su materialización en fundaciones pías, me remito a DÍAZ RODRÍGUEZ, 46 (Palermo, 2019): 277-314.

${ }^{60}$ Testamento del doctor Bartolomé Olalla de Rojas, AHPSE, Protocolos Notariales de Sevilla, leg. 12.696, fols. 558r.-568r.

Hispania, 2020, vol. LXXX, n. ${ }^{\circ}$ 265, mayo-agosto, págs. 405-438, ISSN: 0018-2141, e-ISSN: 1988-8368 https://doi.org/10.3989/hispania.2020.011 
uno de ellos, nos limitaremos a sondear su actividad a lo largo de un año ante el escribano Gaspar de León. Entre el 31 de diciembre de 1597 y el 19 de diciembre de 1598 fueron elevadas a públicas 77 obligaciones o conciertos con la compañía, forma bajo la que se recogen todos los contratos. En ellos, la parte contratante se obligaba a pagar a los curiales contratados a cambio de que éstos se encargaran de solicitar, hacer expedir y traer por correo desde Roma el breve o bula requerido, así como de mover el crédito necesario.

Esto último era un punto clave de la negociación. Podía suceder que los clientes pagaran todo por adelantado, pero fue algo excepcional en los casos analizados. Por lo general, recurrían a servicios crediticios y lo hacían al menos en dos ocasiones. La primera, para el pago de un adelanto al curial, que con Rojas suele hacerse casi siempre en forma de libranzas a su favor sobre la compañía de Pedro de la Torre Espinosa o su hermano, Juan Castellanos de Espinosa ${ }^{61}$. La segunda, para el pago de la expedición en Roma, donde se ofreció siempre la posibilidad de recurrir al crédito de la banca del propio Fonseca (una opción que obviamente no todas las compañías curiales tuvieron) o al crédito de otro banco con el obligado título de mercator Curiam sequens ${ }^{62}$. El capital se enviaba a la corte romana por medio de letras de cambio, directamente o por vía de feria. En este caso, un circuito habitual a fines del XVI iba de Sevilla a Besanzón, donde la letra era negociada en la feria de Piacenza y desde allí a Roma, a veces pasando antes por la plaza de Florencia ${ }^{63}$.

Las comisiones de los curiales en la Península y las de sus corresponsales en Roma se expresaban por separado. Los primeros fijaban de antemano el dinero que cobrarían en concepto de agencia y por el uso de su línea de crédito, o sea, «por el riesgo de poner el dinero en Roma y por su industria y trabajo que

${ }^{61}$ De no entregarse nada a cuenta, es probable que Rojas cobrara más por su agencia. Al menos eso parecen indicar las referencias en que se especifica esa comisión por los «riesgos que ha de correr, pues no le dan dinero adelantado», Obligación otorgada por el licenciado Alonso Álvarez de Córdoba, AHPSE, Protocolos Notariales de Sevilla, leg. 12.584, fol. 1.068r.

${ }^{62}$ Para ello, junto con la escritura de obligación o concierto, a menudo se pedía al cliente que otorgara poder notarial, para con él obligarlo Gomes o Fonseca ante un notario del auditor de la Cámara al pago de pensiones o para tomar dinero prestado a cambio. El cliente se comprometía, además, a pagar también «las costas, daños e yntereses, cambios e recambios que resultaren si en el dicho medio y término no pagáremos», Obligación otorgada por el contador Pedro Marroquín, AHPSE, Protocolos Notariales de Sevilla, leg. 12.584, fol. 331v.

63 A partir de estudios de la casa comercial de Simón Ruiz como el de PINTO, 2012, sabemos del significativo papel jugado en este circuito de crédito desde y para la curia romana por la compañía castellana, si bien la función de la plaza de Roma en estas letras de cambio renegociadas es mucho más recurrente como local de emisión que de pago. Conviene señalar que tanto el doctor António Gomes como el doctor Fonseca actuaron como contactos de Simón Ruiz en Roma, y que la compañía de Fonseca y Rojas recurrió para la emisión de letras de cambio en Sevilla a los servicios de Pedro de Tolosa, agente de Simón Ruiz en la ciudad andaluza.

Hispania, 2020, vol. LXXX, n. ${ }^{\circ} 265$, mayo-agosto, págs. 405-438, ISSN: 0018-2141, e-ISSN: 1988-8368 https://doi.org/10.3989/hispania.2020.011 
a de tener en este negocio», independientemente del monto fina $l^{64}$. En función de la solvencia del cliente, Rojas podía exigir el aval de bienes, además de los muy habituales fiadores ${ }^{65}$. Una vez expedida la letra apostólica, uno de los socios en Italia remitía a Sevilla una factura o «lista por menudo, firmada de su nombre, [de lo que] avisare aber gastado ansí de compuçiçión y cambio de poner el dinero en Roma y lo que se tasare a sí propio por su solisitud y las costas que más montaren la espedición y despacho de las bulas» ${ }^{66}$.

TABLA 2. Tipología de los contratos documentados para 1598

\begin{tabular}{|c|c|c|c|}
\hline Tipo de negocio & Número de contratos & Porcentaje & Capital movilizado \\
\hline Beneficial & 22 & $28,57 \%$ & Desconocido \\
\hline Matrimonial & 34 & $44,15 \%$ & $3.230 .475 \mathrm{mrs}$. \\
\hline Varia & 21 & $27,27 \%$ & $369.135 \mathrm{mrs}$. \\
\hline
\end{tabular}

Fuente: AHPSE, legs. 12.583-12.590. Elaboración propia.

Como puede observarse en la tabla 2, las solicitudes de dispensas matrimoniales fueron el tipo de contrato más habitual, con un $44,15 \%$ del total de ese año. Sobre la propiedad o sucesión de beneficios eclesiásticos versó apenas el $28,57 \%$ de los contratos, una cifra similar a la que suman los negocios de otra índole (27,27\%), esto es, solicitudes de breves y bulas cuya materia no fue ni matrimonial ni beneficial, como veremos a continuación. Sin embargo, la importancia pecuniaria de cada una de estas tres categorías no se corresponde con el peso cuantitativo de los contratos, puesto que los relativos a beneficios eclesiásticos movilizaron entre Sevilla y Roma muchísimo más dinero que el resto en su conjunto.

Dada la diferente forma de negociación de la materia beneficial, resulta arriesgado aventurar una cifra, pero hablamos de cantidades anuales muy por encima de los casi 3,6 millones de maravedís que montan las otras dos partidas.

${ }^{64}$ Obligación otorgada por Lorenzo Fernández de la Peña, AHPSE, Protocolos Notariales de Sevilla, leg. 12.583, fol. $514 \mathrm{v}$.

${ }^{65}$ Sirvan un par de ejemplos: para la resigna pensionada de una media ración que le encargó el licenciado Bartolomé Serafino, éste dio como aval un censo de mil ducados; Francisco Calvarte, para una dispensa matrimonial de primer con segundo grado de consanguinidad, presupuestada en 520.000 maravedís, obligó la plusvalía de unas casas arrendadas en Sevilla. Ambas escrituras en AHPSE, Protocolos Notariales de Sevilla, leg. 12.583, fols. 268r.-270r. y 324r.-325v.

${ }^{66}$ Obligación otorgada por Pedro de Tapia, AHPSE, Protocolos Notariales de Sevilla, leg. 12.584 , fol. $1.009 \mathrm{v}$. 
Tan sólo el coste de una bula de coadjutoría para una canonjía de la catedral de Sevilla se movió, por entonces, entre el millón cincuenta mil y el millón ciento veinticinco mil maravedís por lo general, por no mencionar la superior cuantía que desembolsaron algunos de los clientes de ese año para hacerse con dignidades como la chantría de Cádiz, el arcedianato de Niebla o el de Béjar ${ }^{67}$. Claro está que también se gestionaron bulas para beneficios de menor valor, beneficios parroquiales, capellanías, medias raciones, raciones enteras de catedrales, prebendas de colegiatas, prestameras... Ha quedado rastro documental de los gastos de agencia cobrados por Rojas en el $81,8 \%$ de estos negocios beneficiales. La minuta del corresponsal de Sevilla parece haber oscilado entre el 5,5\% y el $11,5 \%$, según el tipo de asunto, pero ciñéndonos a la cifra mínima para realizar una extrapolación, estaríamos hablando de entre 7,5 y 9 millones de maravedís como poco y pecando, quizá, de excesiva parquedad en el cálculo.

Traducido a cifras redondas y globales, los negocios curiales contratados en Sevilla con el doctor Bartolomé Olalla de Rojas y sus socios pudieron movilizar hacia Roma en un año, como 1597 o 1598, entre los treinta y los treinta y cuatro mil ducados, siendo prudentes, una cantidad nada desdeñable en cualquier otro campo de negocios. Obviamente sus ganancias como intermediario fueron apenas un porcentaje de estas cantidades, si bien hemos de tener en cuenta que el granadino no era el único socio de Fonseca y Gomes, que tenían asimismo correspondencia con otros puntos de la Península Ibérica. Cabe preguntarse qué capital salió desde ésta hacia Italia, pero el desconocimiento de esta realidad mercantil nos impide aún sacar conclusiones cuantitativas fundamentadas ¿Cuánto se negoció desde la capital hispalense cada año, sumando a lo negociado por Rojas los otros tantos contratos llevados a cabo por otros curiales que prestaban sus servicios en la ciudad? ¿Cuánto en el conjunto de los territorios ibéricos, en ciudades como Burgos, Lisboa, Córdoba, Madrid, Úbeda, Barcelona, Granada, Murcia... donde también se documenta la presencia de curiales?

\section{La tipología de las solicitudes}

El mercado matrimonial, en una sociedad católica como la que conformó las clientelas de estos negociantes de la gracia papal, estaba marcado por dos factores en conflicto. De una parte, el amplio abanico de prohibiciones canónicas que restringían las posibilidades de enlace no incestuoso dentro de amplias parentelas, unidas por lazos de sangre, pero también sólo por afinidad (parentesco civil, verbigracia entre cuñados o concuñados) y parentesco espiritual (el

${ }^{67}$ Los encargos de las bulas para estos beneficios concretos en AHPSE, Protocolos Notariales de Sevilla, leg. 12.588, fols. 775 r.-776v., leg. 12.584 , fols. $1.067 \mathrm{v} .-1.069$ r., y leg. 12.589, fols. $145 \mathrm{v} .-147 \mathrm{v}$, , respectivamente.

Hispania, 2020, vol. LXXX, n. ${ }^{\circ} 265$, mayo-agosto, págs. 405-438, ISSN: 0018-2141, e-ISSN: 1988-8368 https://doi.org/10.3989/hispania.2020.011 
derivado de las relaciones de compadrazgo, padrinazgo y prohijamiento). De otra parte, la práctica habitual de la endogamia, fuera por motivos estratégicos o de simple necesidad, convirtió la solicitud de dispensas matrimoniales en algo muy común. En consecuencia, la tramitación de este tipo de breves apostólicos que hicieran posible el casamiento deseado fue el servicio más recurrentemente prestado por cualquier curial.

Como primer paso de la negociación, los oradores o beneficiarios de la futura dispensa debían informar con detalle de todas sus circunstancias, tanto por cuestiones presupuestarias como de trámite: lugares de naturaleza, grados de parentesco conocido entre los contrayentes, si éste era de consanguinidad, de afinidad o doble, si habían mantenido previamente relaciones sexuales o si la promesa de matrimonio u otros hechos podían conllevar escándalo y deshonra familiar en caso de no celebrarse el matrimonio. Solía expresarse la condición social de los oradores, ya que también el coste podía variar en función del estatus. Quienes cumplían ciertos requisitos de pobreza y desamparo podían solicitar su dispensa por la vía más barata (in forma pauperum). En el otro extremo, en aquellos casos no justificables más que por una cuestión de cali$\mathrm{dad}$, esto es, de homogamia entre miembros de las élites locales, hallamos las dispensas más caras. Son las llamadas dispensas sine causa, «dispensas para nobles o para personas de honestas familias» ${ }^{68}$.

Con todos esos datos, Bartolomé Olalla de Rojas podía ofrecer un presupuesto al cliente. Se trataba de un precio cerrado para las dispensas de tercero o cuarto grado, que contaban con una tarifa establecida. En cambio, las dispensas de primer y segundo grado:

... sean para ricos o para pobres, es incierto su coste, porque el dispensarlas es arbitrario, y en tales dispensas solo se puede dezir, que quánto ofreze la parte, y avisarlo al agente para que si puede la obtenga en aquella cantidad, y si no que aguarden los contrayentes que venga de Roma razón de lo que costará. No conviene que el curial pregunte al agente de Roma quanto costarán dichas dispensas, porque no puede dar razón cierta hasta que las tenga ajustadas con el Datario ${ }^{69}$.

Para ello, cualquier compañía curial contaba con tablas de referencia elaboradas a partir de las tarifas vigentes y otra información remitida por los

${ }^{68}$ Práctica de la Dataría con la tarifa justa de las expediciones en las materias beneficiales, matrimoniales y breves, BNE, mss. 7.890, fol. 4v. Por citar apenas un par de ejemplos, así se expresó en la solicitud de dispensa para Juan de Vargas y Mari Blasca Martínez, vecinos de La Higuera, cerca de Fregenal, «por ser de la gente onrada y prinçipal de la dicha villa, sin dar otra causa alguna», o en la de Bartolomé de Barrionuevo, vecino de Gibraltar, y doña Estefanía de Mendoza, vecina de Vejer de la Frontera, siendo "gente prinçipal, sin dar otra causa», AHPSE, Protocolos Notariales de Sevilla, leg. 12.584, fols. 482v. y 509r.

${ }^{69}$ Papeles varios, BNE, mss. 10.994. 
corresponsales en la curia romana. Cuando hemos conservado escrituras de constitución de la compañía, no es raro encontrar entre las condiciones la obligación del socio en Roma de enviar información con este fin, así como la del socio en la Península de reelaborar esos datos en forma de tablas que puedan servir para cerrar un precio con los contratantes ${ }^{70}$. La ilustración 1 reproduce una de estas tablas referidas en la documentación, en que se recogen las tasas de composición y expedición de la Curia (expresadas en escudos de oro y julios), a lo que habría que sumar los gastos de tramitación, agencia, cambios y envío postal de los curiales.

ILUSTRACIÓN 1. Tabla de tasas curiales para dispensas según grado y circunstancias

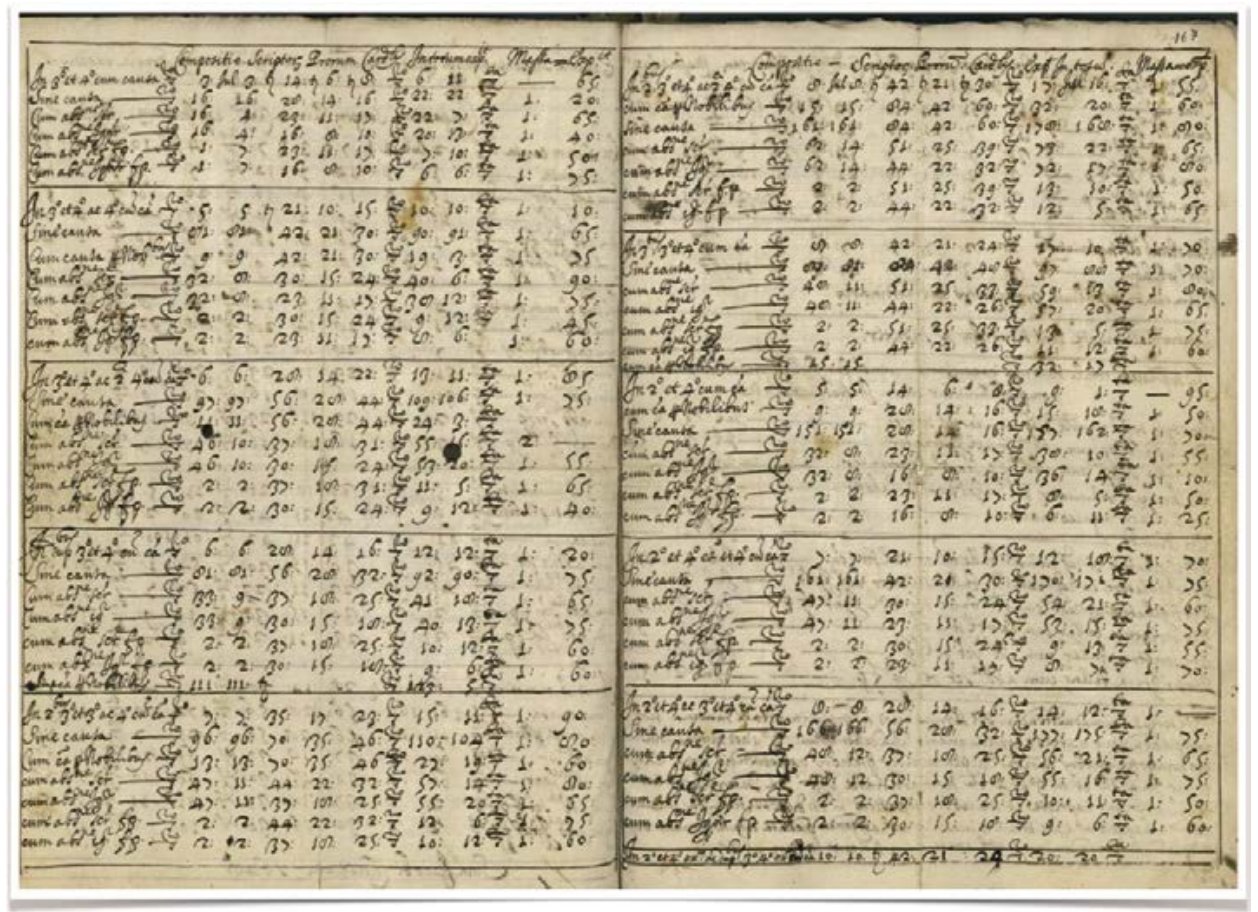

Fuente: Libro de tarifas, dispensas, negocios, bulas y expediciones, BNE, Mss. 6.277, fols. 166v.-167r.

${ }^{70}$ Un muy buen ejemplo fue transcrito y publicado por MADURELL I MARIMON, 36/1 (Tarragona, 1963): 119-122. No me ha sido posible por el momento localizar la escritura de constitución de la compañía de Fonseca y Rojas en la que se recogían las condiciones de esta asociación, probablemente elevada a pública en Roma ante uno de los notarios del auditor de la Cámara Apostólica. Conservamos, eso sí, varias referencias a la existencia de dicha compañía entre ellos, así como a la condición de socios de sus componentes en diversas escrituras. 
Además, la información aportada por el cliente servía para elaborar un memorial justificativo que Rojas remitía a Gomes o a Fonseca, con indicación del presupuesto dado, el plazo para lograr la expedición, la forma de pago y la referencia del expediente.

La tabla 3 recoge el coste documentado para todos los tipos de dispensas matrimoniales cuya expedición fue contratada a lo largo del año 1598. En ella se dan ciertas variaciones de precios, debido precisamente a las condiciones justificantes que podían hacer subir o bajar la componenda a pagar, conocidas como primeras y segundas causas. Entre las primeras estaban la pobreza, la reconciliación entre familias enemigas, la amenaza de pleito o escándalo de no contraerse el matrimonio, la falta de dote o la superación de los 24 años de edad de la mujer; por todo ello la componenda era simple. Por otras causas, como la estrechez del lugar, la mejora de dote o la falta de iguales sociales con que casar, la componenda era doble.

TABla 3. Coste de dispensas matrimoniales documentadas para 1598

\begin{tabular}{|c|c|}
\hline Grado de parentesco & Precios mínimos y máximos en ducados de oro castellanos \\
\hline $1^{\circ} \operatorname{con} 2^{\circ}$ & $1.333,33-1.413,33$ \\
\hline $2^{\circ}$ & $700,00-800,00$ \\
\hline $2^{\circ} \operatorname{con} 3^{\circ}$ & $70,00-152,50$ \\
\hline $2^{\circ} \operatorname{con} 4^{\circ}$ & 60,00 \\
\hline $3^{\circ}$ & $36,36-75,00$ \\
\hline $3^{\circ} \operatorname{con} 4^{\circ}$ & $17,00-36,00$ \\
\hline $4^{\circ}$ & $11,00-35,00$ \\
\hline
\end{tabular}

Fuente: AHPSE, legs. 12.583-12.590. Elaboración propia.

En líneas generales, se trata de cuantías extrapolables a otros puntos del sur peninsular, si los comparamos con los que se negociaban en ciudades próximas. Por ejemplo, para los años 1596-1598, la compañía de Gaspar de la Guerra y Bartolomé Francés cobraba en Córdoba entre 14 y 36 ducados por una dispensa de cuarto grado, unos 20 ducados por una de tercero con cuarto, 45 por una de tercer grado, entre 63 y 180 por una de segundo con tercero... es decir, cifras más o menos dentro de los márgenes en que se movían en esas mismas fechas Fonseca, Gomes y Rojas en Sevilla ${ }^{71}$.

${ }^{71}$ Los datos para Córdoba proceden de varias escrituras de obligación localizadas en el AHPCO, Protocolos Notariales de Córdoba, legs. 10.745, 10.746 y 10.747. 
La tabla no recoge los precios de negocios dispensacionales más complicados, en que los contrayentes eran parientes por varios costados. Muy a menudo y salvo complicaciones, el precio de tales dispensas matrimoniales venía a equivaler a la suma de las dispensas de cada grado por separado. Cabía no obstante una cierta negociación en el precio, al solicitarse un único breve que dispensara todos los lazos de parentesco de una vez en lugar de un breve para cada grado, que encarecería un poco el negocio. Esto podía suceder cuando los clientes olvidaban o desconocían en el momento de la firma del contrato algún parentesco entre sus familias.

Es lo que le pasó al licenciado Lope de Molina Herrera, abogado de la audiencia de Sevilla, quien había contratado el 10 de junio de 1596 al doctor Rojas para la expedición de una dispensa con la que pudieran casarse su hija, doña Isabel de Torres, con don Juan de Herrera. Seis días más tarde Molina acudió a Rojas para renegociar el precio, puesto que alguien les había recordado que los futuros esposos eran no sólo primos hermanos, sino también doblemente parientes en tercero con cuarto grado de consanguinidad por dos costados distintos. Aunque por escritura Rojas se comprometió a intentar incluirlo todo en el mismo breve (siempre que pagaran 700 ducados por adelantado), su corresponsal en Roma ya había iniciado los trámites para cuando le llegó el nuevo aviso. El 24 de septiembre de 1596 se les hizo entrega de la dispensa del segundo grado, mientras que la del doble tercero con cuarto no llegó hasta el 31 de enero del año siguiente. Sólo tuvieron que pagar por esta última cuarenta ducados más de lo presupuestado, ya que el olvido se había notificado en menos de una semana ${ }^{72}$.

Si el lapso temporal era mayor o se sospechaba un intento de fraude contra la fiscalidad pontificia, la dispensa se daba por nula y el matrimonio, de haberse celebrado, por incestuoso. Esto hacía necesario no sólo pedir otra dispensa del parentesco no declarado, sino una letra apostólica de subsanación del breve original (un perinde valere). El 12 de noviembre de 1597, Juan Castellanos de Guzmán, alcaide de los alcázares de Carmona, había contratado por cuarenta ducados al doctor Rojas para traer de Roma una dispensa de tercer grado de afinidad con la que pudieran contraer matrimonio Bartolomé de Cea y doña Catalina de Sanabria Caro. Más de mes y medio después, comunicaron a Rojas a través de don Rodrigo de Quintanilla, asimismo vecino de Carmona, que había «aparecido» que eran además parientes en tercero con cuarto de afinidad por otro de sus costados. A diferencia del caso anterior, en esta ocasión el curial advirtió de que, aparte de los veinte ducados de más que tendrían que pagar por la nueva dispensa, era probable que tuvieran que desembolsar los

72 Obligaciones otorgadas por el doctor Lope de Molina, AHPSE, Protocolos Notariales de Sevilla, leg. 12.571, fols. 240v.-241r. y 714r.-v.

Hispania, 2020, vol. LXXX, n. ${ }^{\circ} 265$, mayo-agosto, págs. 405-438, ISSN: 0018-2141, e-ISSN: 1988-8368 https://doi.org/10.3989/hispania.2020.011 
veinte escudos de oro (8.000 maravedís) que costaba un perinde valere de ese tipo $^{73}$.

Los negocios de materia beneficial movían mucho más dinero, pero también eran incomparablemente más complejos. Entre las décadas de 1580 y 1600 he podido rastrear la presencia de curiales en otras ciudades andaluzas importantes dentro del área de acción de Bartolomé Olalla de Rojas, pero la actividad de intermediación de éstos aún se limitaba a las dispensas matrimoniales. Así ocurre, por ejemplo, en el caso de Córdoba, en todos los contratos que he podido documentar de los curiales Gaspar de la Guerra y Gonzalo de Alcántara en los protocolos notariales entre 1596 y 1602. De hecho, a lo largo de 1598, clientes de Cádiz o de Córdoba (diócesis que no estaban, como Málaga o Granada, mediatizadas por el Patronato Regio y, por tanto, disponían de una dinámica beneficial completamente integrada dentro del mercado curial) fueron hasta Sevilla a contratar los servicios de Bartolomé Olalla de Rojas, como recoge la tabla 4.

TABLA 4. Muestra de negocios beneficiales extradiocesanos

\begin{tabular}{|c|c|c|c|}
\hline Negocio & Solicitantes & Lugar & Fecha \\
\hline $\begin{array}{c}\text { Coadjutoría de una ración de la } \\
\text { catedral de Córdoba }\end{array}$ & Varios & Córdoba & $06 / 06 / 1598$ \\
\hline $\begin{array}{c}\text { Resigna pensionada de un } \\
\text { beneficio simple en Palma del Río }\end{array}$ & Miguel de Castillejo & Córdoba & $13 / 06 / 1598$ \\
\hline $\begin{array}{c}\text { Breve in foro conscientiae } \\
\text { Bula especial para una cofradía }\end{array}$ & $\begin{array}{c}\text { Francisco Díaz de Ruy de Santa Cruz de } \\
\text { Díaz }\end{array}$ & Córdoba & $03 / 07 / 1598$ \\
\hline $\begin{array}{c}\text { Coadjutoría de la chantría de la } \\
\text { catedral de Cádiz }\end{array}$ & $\begin{array}{c}\text { Domingo de Echerreaga } \\
\text { Cádiz }\end{array}$ & $25 / 08 / 1598$ \\
\hline $\begin{array}{c}\text { Coadjutoría del arcedianato de } \\
\text { Béjar y canonjía de la catedral de } \\
\text { Plasencia }\end{array}$ & Varios & Córdoba & $05 / 11 / 1598$ \\
\hline $\begin{array}{c}\text { Coadjutoría de una ración de la } \\
\text { catedral de Córdoba }\end{array}$ & $\begin{array}{c}\text { Pedro de Porras Angulo } \\
\text { Córdoba }\end{array}$ & $07 / 11 / 1598$ \\
\hline
\end{tabular}

Fuente: AHPSE, Protocolos Notariales de Sevilla, legs 12.585-12.589. Elaboración propia.

73 Obligación otorgada por don Rodrigo de Quintanilla, AHPSE, Protocolos Notariales de Sevilla, leg. 12.583, fols. 32r.-33r.

Hispania, 2020, vol. LXXX, n. ${ }^{\circ}$ 265, mayo-agosto, págs. 405-438, ISSN: 0018-2141, e-ISSN: 1988-8368 https://doi.org/10.3989/hispania.2020.011 
En ninguno de estos casos se requirió al doctor Rojas para gestionar una dispensa matrimonial, como puede observarse. Existía un espacio desarrollado para la intermediación curial en esos asuntos en otras ciudades próximas, pero la clientela de esta gran área había de continuar recurriendo a Sevilla para negocios de mayor envergadura como resignas, pensiones, coadjutorías de beneficios o gracias de tipo más extraordinario.

Contratos como los firmados por los cordobeses Miguel de Castillejo o Pedro de Porras Angulo ejemplifican bien la complejidad que hacía necesario el recurso a intermediarios profesionales como Rojas y Fonseca. En el primero de ellos, se trataba de la expedición de la resigna del beneficio simple no servidero en la villa de Palma que pretendía hacer don Francisco Manuel de Guzmán en favor de Castillejo, a cambio de que éste le pagara una pensión vitalicia sobre los frutos: la dificultad estribaba en justificar en Roma que dicha pensión equivaliera a casi el $65 \%$ de las rentas anuales del beneficio ${ }^{74}$. Pensiones que montaran más de la mitad de los frutos estaban contempladas, sencillamente tales solicitudes eran más caras y su negociación en la Dataría era diferente y algo más compleja ${ }^{75}$. En el segundo caso, los solicitantes (Pedro de Porras, en nombre propio y en el de su hijo, don Juan Fernández de Córdoba) recurrieron a los servicios de Rojas y Fonseca para intentar solucionar un problema: habían confiado la expedición de la bula de coadjutoría con futura sucesión en la ración que el pintor Pablo de Céspedes gozaba en la catedral de Córdoba a dos parientes que residían en Roma, don Andrés Fernández de Córdoba, auditor de la Rota, y Pedro Clavijo de Angulo, racionero medio de la misma catedral. A pesar de las buenas intenciones y de la implicación de no pocos individuos de peso (incluido el secretario del rey y compañero de cabildo Mateo Vázquez de Leca) el resultado hasta entonces había sido poco alentador y el gasto de tiempo y dinero demasiado elevado, como hicieron constar en la escritura. Convencidos de que más valía pagar a profesionales, contrataron los servicios de la compañía de Fonseca, Gomes y Rojas a finales de 1598, «para traer a España la dicha bula». En la primavera de 1599 el cliente por fin se dio por entregado de la letra apostólica, al precio de casi quince mil quinientos reales de plata, un precio que seguramente habría sido menor de haber contratado a un especialista desde el principio ${ }^{76}$.

${ }^{74}$ Obligación otorgada por Miguel de Castillejo, AHPSE, Protocolos Notariales de Sevilla, leg. 12.586, fols. 822r.-824r.

75 Resulta llamativo lo poco que sabemos aún sobre un instrumento de la trascendencia de las pensiones eclesiásticas en la Edad Moderna. Desde el punto de vista canónico de su definición, tipología y funcionamiento, sigue siendo referencia obligada GASS, 1942.

${ }_{76}$ Obligación otorgada por Pedro de Angulo, AHPSE, Protocolos Notariales de Sevilla, leg. 12.589, fols. $1.101 \mathrm{r} .-1.105 \mathrm{v}$.

Hispania, 2020, vol. LXXX, n. ${ }^{\circ} 265$, mayo-agosto, págs. 405-438, ISSN: 0018-2141, e-ISSN: 1988-8368 https://doi.org/10.3989/hispania.2020.011 
A veces no era la tramitación en sí lo complicado, sino las circunstancias del negocio o de los solicitantes. Esa fue la causa para contratar la expedición de una bula de coadjutoría con futura sucesión irrevocable en la chantría de la catedral de Cádiz en favor de Domingo de Echerreaga. En la práctica, eso significaba la adquisición del derecho de sucesión en esta dignidad. Muchos eclesiásticos aceptaban coadjutores en sus prebendas, bien porque se tratase de un pariente que viniera a sucederle, bien por un acuerdo económico con un particular. Pocos propietarios estaban en una situación tan desesperada como la del chantre de Cádiz, don Diego de Mendoza Santotis. Había sido apresado en el ataque inglés a Cádiz de 1596 y se le exigía un elevado rescate. Necesitaba obtener dinero por cualquier medio, si no quería terminar sus días como varios de sus compañeros de cabildo, ahorcados por el conde de Essex ${ }^{77}$. En lo que cupiera pagar al chantre, bien podía ayudar la venta encubierta de una dignidad eclesiástica, por lo que envió poder notarial desde Inglaterra con el que Fonseca, Gomes y Rojas pudieran negociar su solicitud de un coadjutor en la Dataría Apostólica ${ }^{78}$.

Encontramos incluso un contrato referente a la sucesión en una dignidad y canonjía en la catedral de Plasencia a favor de don Francisco de Gamboa y Eraso. La he incluido en la tabla por ser los contratantes cordobeses. Don Alonso de Gamboa y Valenzuela y su mujer, doña Ana de Gamboa, vecinos de Baena, en nombre de don Francisco (ausente en Salamanca, en cuya universidad impartía clases de Derecho Canónico), dieron poder notarial a su pariente Don Alonso Venegas de Cañaveral, canónigo de la catedral de Córdoba, para ir a Sevilla a contratar a un curial por la cantidad de dinero que fuera necesaria pagar «del costo y costa de ganar las bulas de Su Santidad para el arcedianato de Béjar, dignidad en la iglesia de Plasencia, y canonicato de la propia iglesia». Pertenecían al doctor don Juan Evangelista Ruano, que se había avenido a aceptar en sus beneficios a Gamboa como futuro sucesor. La entrega de la bula, una vez expedida, tendría lugar en Córdoba, Baena o Salamanca, a petición de los interesados ${ }^{79}$.

El resto de negocios, englobados en la tabla 1 como varia, fueron solicitudes de dispensas de otro tipo, indulgencias, confirmaciones y otras materias raras competencia de la Penitenciaría Apostólica, del Tribunal de la Signatura o de la Congregación del Concilio. En tanto que asuntos mucho menos comunes, la comisión de agencia de Rojas solía ser mayor que en negocios más habituales como coadjutorías, pensiones o dispensas matrimoniales. En los más

77 ABREU, 1866: 47.

78 Obligación otorgada por Domingo de Echerreaga, AHPSE, Protocolos Notariales de Sevilla, leg. 12.588, fols. 775r.-776v.

79 Obligación otorgada por don Francisco de Gamboa, AHPSE, Protocolos Notariales de Sevilla, leg. 12.589 , fols. $839 \mathrm{v} .-846$ r.

Hispania, 2020, vol. LXXX, n. ${ }^{\circ}$ 265, mayo-agosto, págs. 405-438, ISSN: 0018-2141, e-ISSN: 1988-8368 https://doi.org/10.3989/hispania.2020.011 
complicados, como la dispensación de ciertos defectos canónicos graves por la Penitenciaría, podía llegar a ser de más del doble. Es a lo que hace referencia, por ejemplo, el autor de La Lozana andaluza, cuando en el mamotreto XXXVII de la obra pone a discutir a la protagonista con un cliente (Patrón), oficial de la curia romana, por el precio de los favores sexuales de Angélica:

Patrón.- (...) y le daré seis ducados cada mes, y no quiero sino dos noches cada semana. Ved vos si merece más, y por lo que dijéredes me regiré.

Lozana.- Señor, digo que no es muncho, aunque le diésedes la meatad de vuestro oficio de Penitencería. Mas ¿cómo haremos? Que si vuestra merced tiene ciertos defectos que dicen, será vuestra merced perder los ducados y yo mis pasos.

Patrón.- ¿Cómo, señora Lozana?¿Y suelo yo pagar mal a vuestra merced? Tomá, veis ahí un par de ducados, y hacé que sea la cosa de sola signatura ${ }^{80}$.

Como otras muchas referencias literarias en este sentido del propio Francisco Delicado, pero también de autores (asimismo de origen converso, curiosamente ${ }^{81}$ ) como Fernando de Rojas, Bartolomé de Torres Naharro, Alfonso de Valdés o Luis de Góngora, ha sido malinterpretada por desconocimiento de este fenómeno. Me parece indiscutible que todo el pasaje es un paródico juego de Francisco Delicado entre el mercado del sexo y el mercado curial en la Roma de su tiempo y no, desde luego, de la solicitud, un tanto peregrina, del cliente a la prostituta «para que los trámites del negocio se simplifiquen a una sola firma», como leen algunos editores literarios ${ }^{82}$.

\section{CONCLUSiones}

Individuos de la perspicacia de Juan XXII y León X, entre otros, sentaron a lo largo de la Baja Edad Media y la temprana Edad Moderna las bases de la fiscalidad espiritual pontificia, expandiendo tanto el abanico de prohibiciones

80 DELICADO, 2013: 193.

${ }^{81}$ Ha podido profundizar en varios aspectos de la estrecha relación entre el mercado curial y el mundo judeoconverso, como son la fuerte presencia conversa entre los agentes de negocios curiales, el peso del mercado curial en el acceso de los conversos al clero catedralicio, o la proyección patrimonial de todo ello. DÍAZ RODRÍGUEZ, 6 (Jerusalén, 2016c): 13-33; 4 (Santa Barbara, 2016d): 38-63; 46 (Palermo, 2019): 277-314.

82 DELICADO, 2013: 193, nota 46. De hecho, el personaje de Patrón está haciendo alusión a un tipo específico de solicitud que podían presentar los curiales, las llamadas peticiones con cláusula de sola signatura, por las que podía comenzar a dar por válida la gracia una vez registrado el documento por un oficial, a la espera de expedirse la bula o breve papal de la gracia en toda su legalidad. Era un medio barato y rápido para dinamizar ciertas operaciones, por ejemplo, una resigna in favorem en que peligrara la sucesión en el beneficio si el propietario no parecía capaz de resistir vivo los quince días de plazo mínimos.

Hispania, 2020, vol. LXXX, n. ${ }^{\circ} 265$, mayo-agosto, págs. 405-438, ISSN: 0018-2141, e-ISSN: 1988-8368

https://doi.org/10.3989/hispania.2020.011 
canónicas, como la capacidad de acción del papado en materia beneficial o de dispensación de esas mismas prohibiciones, además de otros aspectos eclesiásticos. Poco a poco, en torno a un bien no mercantil ni venal, gratuito por definición como lo era la gracia papal, se gestó un espacio transnacional de negociación entre clientes (los fieles), intermediarios, financieros, especuladores y el último y único proveedor (la Curia pontificia). Lo más interesante de todo ello es la propia génesis del fenómeno: ese único proveedor había creado la necesidad y la necesidad crearía el mercado; un enorme mercado eclesiástico hasta entonces inexistente.

En las décadas de efervescencia y expansión que a inicios de la temprana época moderna vivían las sociedades ibéricas, el mercado curial fue una válvula de escape para la presión acumulada. Grupos urbanos pujantes vieron la oportunidad de invertir en un nuevo mercado que no les ofrecía meramente títulos de renta atractivos por su seguridad o instrumentos con que salvar trabas legales - al matrimonio entre parientes, al ingreso en el clero, etc.- - sino además el acceso a cargos eclesiásticos con un valor simbólico reconocido: como mínimo honorífico, esto es, generador de honra y distinción (por el estatuto privilegiado inherente) $\mathrm{y}$, en ocasiones, con una potente capacidad de legitimación social ${ }^{83}$.

En consecuencia, al hablar de mercado curial lo hacemos también de un factor y de un espacio determinante para las dinámicas de movilidad social de la España moderna. En la medida en que, para que dicho espacio funcionase, era necesaria la articulación de circuitos de intermediación entre los fieles en la Península Ibérica y los oficiales y banqueros de la curia romana, los curiales fungían una función indefectible.

Es interesante señalar también el carácter hispano-portugués de la sociedad curial tomada como estudio de caso, puesto que, lejos de tratarse de algo casual o anecdótico, refleja bien la completa imbricación de intereses, crédito y redes portuguesas en el mercado curial español, y viceversa, entre la segunda mitad del quinientos y la primera mitad del seiscientos ${ }^{84}$.

En este artículo sólo hemos hablado de una pequeñísima fracción de operaciones de intermediación desde una ciudad española, bien es cierto que de magnitudes desbordantes, como fue la Sevilla de finales del siglo XVI. Por añadidura, he querido ceñirme exclusivamente a las contrataciones documentadas ante un escribano en particular y por un único curial que, sin duda, negoció otras tantas allí, se protocolizaran o no. Es fácil deducir que cientos de miles de ducados, decenas de millones de maravedís, se movilizaron con este objetivo, cada año, desde la Península Ibérica hacia Roma.

${ }^{83}$ DÍAZ RODRÍGUEZ, 6 (Santa Barbara, 2016d): 13-33.

${ }^{84}$ Acerca del papel de los portugueses en las redes económicas en torno a Sevilla, véase FERNÁNDEZ CHAVES y PÉREZ GARCÍA, 25 (Madrid, 2012): 199-222. 
Cifras de este calibre, las redes humanas y los mecanismos comerciales y legales que se descubren a poco que se analice este mercado, o sus enormes repercusiones socioeconómicas y aun culturales en el mundo católico, son elementos suficientes, en mi opinión, para cuestionar por qué se ha ignorado hasta ahora un fenómeno trascendental y fascinante como éste.

\section{Bibliogr AFÍA}

Abreu, Pedro de, Historia del saqueo de Cádiz por los ingleses en 1596, Cádiz, Revista Médica, 1866.

Alcina, Juan F., Repertorio de la poesía latina del Renacimiento en España, Salamanca, Ediciones Universidad de Salamanca, 1995.

Astrana Marín, Luis, Vida ejemplar y heroica de Miguel de Cervantes Saavedra, Madrid, Instituto Editorial Reus, 1952, tomo IV.

Barbosa, Agustín de, Collectanea doctorum, tam veterum quam recentiorum, Lyon, Borde, 1669, tomo VI.

Barrio Gozalo, Maximiliano, El Sistema Beneficial de la Iglesia Española en el Antiguo Régimen (1475-1834), San Vicente del Raspeig, Publicaciones de la Universidad de Alicante, 2010.

Bataillon, Marcel, «La chasse aux bénéfices vue de Rome par Juan Páez de Castro», en Histoire économique du monde méditerranéen, Toulouse, Privat, 1973: 81-93.

Brigante Colonna, Gustavo, La nepote di Sisto V. Il dramma di Vittoria Accoramboni (1573-1585), editado por Ivana Ercolanoni, S. Cesario di Lecce, Manni, 2005.

Casado Alonso, Hilario, «Los flujos de información en las redes comerciales castellanas de los siglos XV y XVI», Investigaciones de Historia Económica, 10 (Madrid, 2008): 35-68.

Delicado, Francisco, La Lozana andaluza, editado por Folke Gernert y Jacques Joset, Madrid, Real Academia Española, 2013.

Delumeau, Jean, Rome au XVIe siècle, París, Hachette, 1975.

Díaz Rodríguez, Antonio J., «Un mercado beneficial: la mercantilización de beneficios eclesiásticos en Castilla y Portugal», en Juan José Iglesias, Rafael M. Pérez García y Manuel F. Fernández Chaves (eds.), Comercio y Cultura en la Edad Moderna, Sevilla, Editorial Universidad de Sevilla, 2015: 1.125-1.140.

Díaz Rodríguez, Antonio J., «El sistema de agencias curiales de la Monarquía Hispánica en la Roma pontificia», Chronica Nova, 42 (Granada, 2016a): 51-78.

Díaz Rodríguez, Antonio J., «El hombre práctico en Roma: familia y méritos en la elección de agentes curiales de la Monarquía Hispánica», en Francisco Sánchez-Montes González, Julián J. Lozano Navarro y Antonio Jiménez Estrella (eds.), Familias, élites y redes de poder cosmopolitas de la Monarquía Hispánica en la Edad Moderna, Granada, Editorial Comares, 2016b: 57-79.

Díaz Rodríguez, Antonio J., «Papal Bulls and Converso Brokers: New Christian Agents at the Service of the Catholic Monarchy in the Roman Curia (1550-1650)», Journal of Levantine Studies, 6 (Jerusalén, 2016c): 13-33. 
Díaz Rodríguez, Antonio J., «Purity of Blood and the Curial Market in Iberian Cathedrals», e-Humanista/Conversos, 4 (Santa Barbara, 2016d): 38-63.

Díaz Rodríguez, Antonio J., «Mercaderes de la gracia: las compañías de negocios curiales entre Roma y Portugal en la Edad Moderna», Ler História, 72 (Lisboa, 2018): 55-76.

Díaz Rodríguez, Antonio J., «Roma y el patrimonio judeoconverso: negocios curiales y ascenso social entre los conversos andaluces (ss. XVI-XVII», Mediterranea: Ricerche Storiche, 46 (Palermo, 2019): 277-314.

Fernández Chaves, Manuel F. y Pérez García, Rafael M., «La penetración económica portuguesa en la Sevilla del siglo XVI», Espacio, Tiempo y Forma, 25 (Madrid, 2012): 199-222.

Fernández Terricabras, Ignasi, «Le rôle des bénéfices ecclésiastiques dans les stratégies familiales au XVIe siècle: l'example de la famille Robuster, entre Rome et Tarragone», en Michel Bertrand (ed.), Pouvoirs des familles, familles de pouvoir, Toulouse, CNRS-Université de Toulouse II-Le Mirail, 2005: 649-668.

Fortea Pérez, José I., «La Hacienda de los Estados Pontificios en los inicios de la Modernidad (1420-1565)», en Ángel Galán Sánchez (ed.), Estados y mercados financieros en el occidente cristiano (siglos XIII-XVI). XLI Semana de Estudios Medievales, Pamplona, Gobierno de Navarra, 2015: 473-508.

Galán Sánchez, Ángel, «Granada y Castilla. Las rentas del rey y los arrendadores de la corona», en Ángel Galán Sánchez (ed.), Estados y mercados financieros en el occidente cristiano (siglos XIII-XVI). XLI Semana de Estudios Medievales, Pamplona, Gobierno de Navarra, 2015: 309-350.

García de Andrés, Inocente, «Santos mártires Félix y Adauto: sus reliquias e iconografía. Roma, el Escorial y Tarancueña (Soria)», en El culto a los santos: cofradias, devoción, fiestas y arte (actas del Simposium 2/5-IX-2008), San Lorenzo del Escorial, Instituto Escurialense de Investigaciones Históricas y Artísticas, 2008: 721-738.

Gass, Sylvester Francis, Ecclesiastical Pensions. An Historical Synopsis and Commentary, Washington, The Catholic University of America Press, 1942.

Girón Pascual, Rafael M., Comercio y poder. Mercaderes genoveses en el sureste de Castilla durante los siglos XVI y XVII, Valladolid, Universidad de Valladolid-Cátedra Simón Ruiz, 2018.

Guidi-Bruscoli, Francesco, Papal Banking in Renaissance Rome. Benvenuto Olivieri and Paul III, 1534-1549, Aldershot, Ashgate, 2007.

Lohmann Villena, Guillermo, «Los regidores andaluces del cabildo de Lima», en Andalucía y América en el siglo XVI, Huelva, CSIC, 1983, vol. 2: 223-272.

Madurell i Marimon, Josep Maria, «Un legista agente de negocios en la curia romana», Analecta Sacra Tarraconensia, 36/1 (Tarragona, 1963): 119-122.

McClung Hallman, Barbara, Italian Cardinals, Reform, and the Church as a Property, 1492-1563, Berkeley, University of California, 1985.

Nelson Novoa, James W., «Between Roman Home and Portuguese Heath. Jerónimo da Fonseca in Rome», Historia y Genealogía, 4 (Córdoba, 2014): 341-356.

Olaechea, Rafael, Las relaciones hispano-romanas en la segunda mitad del XVIII. La Agencia de Preces, Zaragoza, Institución Fernando el Católico, 1999 [1965]. 
Ollero Pina, José Antonio, «Micer García de Gibraleón (1534), un bróker eclesiástico en la Roma del Renacimiento», Hispania. Revista española de Historia, 253 (Madrid, 2016): 355-384.

Otte, Enrique, «Sevilla, plaza bancaria europea en el siglo XVI», en Alfonso Otazu (ed.), Dinero y crédito (Siglos XVI-XIX), Madrid, Moneda y Crédito, 1978: 89-112.

Partner, Peter, «Papal Financial Policy in the Renaissance and Counter-Reformation», Past \& Present, 88/1 (Oxford, 1980): 17-62.

Pinto, Sara María Costa, A Companhia de Simón Ruiz. Análise espacial de uma rede de negócios no século XVI, tesis doctoral, Universidad de Oporto, 2012.

Poncet, Olivier, La France et le pouvoir pontifical (1595-1661). L'esprit des institutions, Roma, École Française de Rome, 2011.

Prodi, Paolo, «Operazione finanziarie presso la corte romana di un uomo di affari milanese nel 1562-63», Rivista storica italiana, 73 (Nápoles, 1961): 641-659.

Re, Niccolò del, La curia romana. Lineamenti storico-giuridici, Ciudad del Vaticano, Libreria Editrice Vaticana, 1998.

Reinhardt, Wolfgang, Papsfinanz und Nepotismus unter Paul V (1605-1621): Studien und Quellen zur Struktur und zu quantitativen Aspekten des päpstlichen Herrschaftssystems, Stuttgart, Hiersemann, 1974.

Rosa, Mario, La curia romana nell'età moderna. Istituzioni, cultura, carriere, Roma, Viella, 2013.

Soria Mesa, Enrique, «Las capellanías en la Castilla moderna», en Antonio Irigoyen López y Antonio L. Pérez Ortiz (eds.), Familia, transmisión y perpetuación (siglos XVI-XIX), Murcia, Universidad de Murcia, 2002: 135-148.

Soria Mesa, Enrique, «El negocio del siglo. Los judeoconversos y la renta de la seda del Reino de Granada (siglo XVI)», Hispania, 253 (Madrid, 2016): 415-444.

Stumpo, Enrico, Il capitale finanziario a Roma tra Cinquecento e Seicento, Milán, A. Giuffrè, 1985.

Valeriano Bolzani, Giovanni Piero, Defensa de las barbas de sacerdotes..., traducción de Mateo de Ribas Olalla, Sevilla, Alonso Rodríguez Gamarra, 1609.

Recibido: 11/03/2019

Aceptado: 17/04/2020

Hispania, 2020, vol. LXXX, n. ${ }^{\circ}$ 265, mayo-agosto, págs. 405-438, ISSN: 0018-2141, e-ISSN: 1988-8368

https://doi.org/10.3989/hispania.2020.011 